\title{
Influence of Ice Nuclei Parameterization Schemes on the Hail Process
}

\author{
Xiaoli Liu $\mathbb{D}^{1},{ }^{1,2}$ Ye Fu, ${ }^{3}$ Zhibin Cao, ${ }^{4}$ and Shuanglong Jin $\mathbb{D}^{5}$ \\ ${ }^{1}$ Key Laboratory of Meteorological Disaster of Ministry of Education, Nanjing University of Information Science and Technology, \\ Nanjing 210044, China \\ ${ }^{2}$ Key Laboratory for Aerosol-Cloud-Precipitation of China Meteorological Administration, Nanjing University of \\ Information Science and Technology, Nanjing 210044, China \\ ${ }^{3}$ Xianyang Meteorology Bureau, Xianyang 712000, China \\ ${ }^{4}$ Purple Mountain Observatory, Nanjing 210008, China \\ ${ }^{5}$ State Key Laboratory of Operation and Control of Renewable Energy \& Storage Systems, China Electric Power Research Institute, \\ Beijing 100192, China
}

Correspondence should be addressed to Xiaoli Liu; liuxiaoli2004y@nuist.edu.cn and Shuanglong Jin; jinshuanglong@epri.sgcc.com.cn

Received 14 August 2017; Revised 7 December 2017; Accepted 21 December 2017; Published 20 February 2018

Academic Editor: Bin Yong

Copyright (C) 2018 Xiaoli Liu et al. This is an open access article distributed under the Creative Commons Attribution License, which permits unrestricted use, distribution, and reproduction in any medium, provided the original work is properly cited.

Ice nuclei are very important factors as they significantly affect the development and evolvement of convective clouds such as hail clouds. In this study, numerical simulations of hail processes in the Zhejiang Province were conducted using a mesoscale numerical model (WRF v3.4). The effects of six ice nuclei parameterization schemes on the macroscopic and microscopic structures of hail clouds were compared. The effect of the ice nuclei concentration on ground hailfall is stronger than that on ground rainfall. There were significant spatiotemporal, intensity, and distribution differences in hailfall. Changes in the ice nuclei concentration caused different changes in hydrometeors and directly affected the ice crystals, and, hence, the spatiotemporal distribution of other hydrometeors and the thermodynamic structure of clouds. An increased ice nuclei concentration raises the initial concentration of ice crystals with higher mixing ratio. In the developing and early maturation stages of hail cloud, a larger number of ice crystals competed for water vapor with increasing ice nuclei concentration. This effect prevents ice crystals from maturing into snow particles and inhibits the formation and growth of hail embryos. During later maturation stages, updraft in the cloud intensified and more supercooled water was transported above the $0^{\circ} \mathrm{C}$ level, benefitting the production and growth of hail particles. An increased ice nuclei concentration therefore favors the formation of hail.

\section{Introduction}

Statistics show that over $50 \%$ of mid-latitude precipitation is caused by the melting of large ice particles produced during the ice-phase transformation process; this ratio is slightly lower $(\sim 30 \%)$ in the tropics [1]. The microphysical process of ice-phase transformation in clouds plays a distinct role in the formation of precipitation particles. Thus, the ice crystal nucleation process is very important [2-4]. Many scholars have studied the distribution characteristics of ice nuclei (IN) and their effects on clouds and precipitation using a combination of observations and numerical simulation results. The results showed that microphysical processes in clouds are affected by changes in the atmospheric thermodynamic environment through artificially propagating IN that can grow into ice crystals. This consequently affects the latent heat release rates, dynamic processes of strong convective clouds, and resultant precipitation particles [5].

Given the fact that effect of IN on strong convective clouds is extremely complex, there are no definite conclusions about the net effects of the concentration of IN on strong convective clouds [6]. Some studies suggest that an increase in the IN concentration favors ground precipitation. For example, a study focusing on the period between the 1940s and the 1960s found that the concentration of ice crystals in cloud with a large volume of aerosols (especially IN) 
transported by upstream winds had increased, leading to increasing rainfall and hail in Indiana, which was affected by urban air pollution during this period [7]. Khain et al. [8] stated that the latent heat released by frozen small cloud droplets enhances the convection in clouds as the IN concentration increases in mixed-phase convection clouds, resulting in increased precipitation. However, sensitivity tests of the IN concentration of strong convective clouds showed opposite effects. van den Heever et al. [9] and Carrió et al. [10] discussed the effects of IN on strong convective clouds in Florida using the Regional Atmospheric Modeling System (RAMS), a highly versatile numerical code developed by scientists at Colorado State University to simulate and forecast meteorological phenomena [11]. The results showed that the number of graupel particles decreases and that of hail particles increases when the aerosol concentration increases. In addition, an increased IN concentration in the early stages of convective clouds leads to increased ground precipitation. However, in the later stages, the aerosol concentration is the lowest when the accumulated precipitation reaches its maximum. Connolly et al. [12] argued that the "frozen indirect effect" produced by the increase in the IN concentration is very small.

Note that the influence of the IN concentration on convective precipitation is very complex and may differ from one location and/or case to another. Observatory IN parameterization reflects the natural distribution and properties of IN under certain conditions and locations, based on which the ice phases in convective clouds initiate and evolve. Thus, it is meaningful to use observatory IN parameterization to explore the role of IN in the development of severe precipitation.

\section{Observation and Brief Review of Parameterization Schemes of Ice Nuclei}

Several IN parameterization schemes have been developed to describe the IN concentration and heterogeneous nucleation process of ice crystals. The fitting equation for the IN concentration obtained from observations is widely used in the model because of its simplicity. In the 1960s, Fletcher [13] used the static filter method for the first time and obtained an empirical equation for the IN concentration that is only related to temperature. However, the nucleation process treated by this diagnostic framework overestimates the concentration of ice crystals and lacks sensitivity to changes in saturation. Several studies also suggested that the nucleation capacity of IN is temperature-dependent [14-16]. Relevant research discussing the atmospheric IN concentration and its variation has also been conducted in China. You et al. [17-19] observed the concentrations of IN and ice crystals in Beijing and Jilin, respectively, and obtained an empirical fitting equation for the correlation between the IN concentration and temperature. The characteristics of IN and their influence on the ice crystal concentration were also discussed.

Many observations have proven that the concentration of ice crystals in clouds is not strictly determined by the temperature $[20,21]$. The deposition nucleation process can be more suitably described by supersaturation with respect to the ice surface [22-24]. This means that, under different supersaturation conditions, IN have different surface properties and the same types of IN can only simultaneously nucleate under the same environmental conditions.

The heterogeneous ice-phase nucleation process is not simply determined by the temperature or ice surface supersaturation. In 1985, Vali [25] proposed for the first time four different mechanisms of heterogeneous ice-phase nucleation including deposition, immersion-freezing, condensationfreezing, and contact-freezing nucleation. However, the relative importance of these mechanisms has not been determined. Relevant studies suggest that $[26,27]$ immersionfreezing and contact-freezing nucleation are most important for mixed-phase clouds, while deposition nucleation is more important in ice clouds above the troposphere. Other studies showed that immersion-freezing and condensation-freezing nucleation play a dominant role in the freezing mechanism [28].

The prediction of the IN concentration in the model is very complex and difficult due to the lack of understanding of the relative importance of the four heterogeneous ice crystal nucleation mechanisms. Meyers et al. [11] first developed empirical relationships for different nucleation mechanisms, which are still widely used in models $[9,10]$.

The deposition and condensation-freezing processes are related to the surface supersaturation relative to ice. Water vapor molecules attach to IN and then form ice crystals through the deposition process, that is, the heterogeneous deposition nucleation process. If the aerosol has both characteristics of cloud condensation nuclei and IN, water vapor molecules first attach to the aerosol and form liquid water droplets, which then freeze into ice crystals, that is, the heterogeneous condensation-freezing nucleation process. The empirical fitting equations for the two processes can be expressed as

$$
N_{i d}=\exp \left\{a+b\left[100\left(S_{i}-1\right)\right]\right\},
$$

where $N_{i d}$ is the concentration of the deposition and condensation-freezing nuclei per liter of air, $S_{i}$ is the saturation relative to the ice surface, $a=-0.639, b=0.1296$, and the applicable temperature range is $-5^{\circ} \mathrm{C}$ to $-20^{\circ} \mathrm{C}$.

No separate observations on contact-freezing nuclei concentration had been obtained until Cooper and Saunders [15] conducted an observation, estimating the concentration of contact-freezing nuclei. Based on Cooper's observation, Meyers et al. developed a fitting equation for the concentration of contact-freezing nuclei, which are temperature-dependent [11]:

$$
N_{i c}=\exp \left[a+b\left(273.15-T_{c}\right)\right] .
$$

If the aerosol diameter is $0.1 \mu \mathrm{m}, T_{c}$ is the cloud droplet temperature (K), $a=-2.80, b=0.262$, and the unit of $N_{i c}$ is $\mathrm{L}^{-1}$.

Following Meyers, the IN parameterization has been developed [29, 30]. China's meteorological researchers carried out a series of IN observation experiments in the upper reaches of the Yellow River [31,32]. It was believed that 
the concentration of IN at different locations showed large fluctuations, leading to changes in the empirical relationship of atmospheric IN concentrations [33-36].

In 2007, Phillips et al. [37] developed an improved IN concentration fitting equation based on Meyers' research by adding the empirical equation developed by DeMott et al. [38] using the continuous-flow diffusion chamber (CFDC) observed at the top of Mount Werner, Colorado, and extending the applicable temperature range of IN activation. This fitting showed that the IN concentration in the continental boundary layer calculated by Meyers' empirical formula is significantly higher than that of the interior of the troposphere (especially at high elevations far from the land source).

Phillips et al. [39] considered the effects of the physical and chemical properties and surface area of IN and developed a new IN concentration equation. Connolly et al. [12] developed a correlation equation between the density of nuclei surface activation sites and IN concentration by studying the immersion-freezing nucleation of dust particles. Recently, Chinese meteorological researchers developed a new empirical fitting equation for IN concentration using observation data from Su [40] and Yang et al.[41].

\section{Introduction of the Case Study and Simulation Framework}

3.1. Introduction of the Case Study and Models. Strong convective weather occurred in a large area of the Zhejiang Province on November 9, 2009. From 06:00 China Standard Time (CST) to 12:00 CST, thick fog appeared in some areas of eastern, northern, and central Zhejiang and lasted for up to six hours. Thunderstorms and strong winds occurred after 15:00 CST throughout the province, representing the most extensive and strongly convective weather that occurred in the autumn of that year. In addition, hail fell at 15:45 CST in the Pujiang County and other places. The hail diameter reached $1.5 \mathrm{~cm}$.

In this paper, numerical simulations using the WRF v3.4 mesoscale model were conducted. Six-hourly global reanalysis data $\left(1^{\circ} \times 1^{\circ}\right)$ from the National Centers for Environmental Prediction (NCEP) were selected as the initial field and boundary data. The integration time of the hail process in the model ranged from 08:00 to 20:00 CST on November 9,2009 . The integration time step was $36 \mathrm{~s}$. The latitude and longitude of the simulation center were $29.60^{\circ} \mathrm{N}$ and $119.80^{\circ} \mathrm{E}$, respectively. Double bidirectional nesting was adopted in the model. From the coarse to fine D01 and D02 areas, the grid resolution was $6.2 \mathrm{~km}$ and the numbers of grid points were $150 \times 160$ and $262 \times 280$, respectively. Twenty-seven layers were used vertically. The microphysical cloud scheme was an NSSL two-moment scheme [42] developed by the US National Severe Storms Laboratory (NSSL) in 2010, which is a hybrid phase cloud framework. With respect to microphysical cloud processes, the model predicts the specific water content $(Q c, Q r, Q i, Q s, Q g$, and $Q h)$ and concentrations $(\mathrm{Nc}, \mathrm{Nr}, \mathrm{Ni}, \mathrm{Ns}, \mathrm{Ng}$, and $\mathrm{Nh}$ ) of six types of hydrometeors (cloud water, rainwater, ice crystals, snow, graupel, and hail particles). The NSSL framework is an improved framework based on the Ziegler framework [43], which can be used to predict the average graupel particle density. The particles ranging from frozen drops to low-density hail embryos are collectively called graupels. Other physical processes were selected as follows: the Monin-Obukhov surface layer scheme, the Mellor-Yamada-Janjic (MYJ) boundary layer scheme, the Noah land surface scheme, the rapid and accurate radiative transfer model (RRTM) for longwave radiation scheme, and the Dudhia for shortwave radiation scheme. The Kain-Fritsch (new Eta) scheme was used for cumulus convection parameterization in the D01 area, while the D02 area was closed.

\subsection{Introduction of Ice Nuclei Parameterization Schemes}

3.2.1. Ice Crystal Nucleation Process in the NSSL Framework. In NSSL, three types of nucleation of ice crystals via IN are considered: deposition, condensation-freezing, and contactfreezing (heterogeneous ice-phase nucleation).

(1) Deposition and Condensation-Freezing Nucleation. There are two scenarios for calculating the IN concentration of the deposition and condensation-freezing processes. First, when the temperature is less than $-5^{\circ} \mathrm{C}$, the empirical relationship of Meyers et al. [11] is used. Second, when the temperature is greater than or equal to $-5^{\circ} \mathrm{C}$, the equation given in Cotton et al. [44] is used:

$$
N_{i}= \begin{cases}n_{i o}\left[\frac{\left(q_{v}-q_{\mathrm{is}}\right)}{\left(q_{\mathrm{ws}}-q_{\mathrm{is}}\right)}\right]^{4.5} \exp (-0.6 T), & T \geq-5^{\circ} \mathrm{C} \\ \exp \left[12.96\left(S_{i}-1\right)-0.639\right], & T<-5^{\circ} \mathrm{C},\end{cases}
$$

where $q_{v}$ is the water vapor mixing ratio, $q_{\text {is }}$ and $q_{\mathrm{ws}}$ are the saturation ratios relative to ice and water, respectively, and $S_{i}=q_{v} / q_{\text {is }}$ is the saturation relative to the ice surface.

(2) Contact-Freezing Nucleation. The parameter $N_{i}$ is the activated contact nuclei concentration (unit: $\mathrm{m}^{-3}$ ) expressed as $N_{i}=\exp \left(4.11-0.262 T_{c}\right)$ and $T_{c}$ is the cloud droplet temperature.

In most of the two-moment microphysical schemes, the IN concentration is used to predict the concentration and mixing ratio of ice crystals. The calculation of the IN concentration is based on simple empirical equations, as shown above, and the initial ice crystal concentrations produced by heterogeneous nucleation are obtained by calculation.

3.2.2. Sensitivity Test of the Ice Crystal Nucleation Process. To better understand the effect of IN on cloud microphysical processes, five additional IN parameterization schemes were employed in this study in addition to the original one. Through comparative experiments, the effects of the six IN parameterizations on the spatiotemporal distribution of ice crystals and other hydrometeors were discussed. The effects of different IN parameterizations on microphysical processes of hail clouds and the occurrence of hailstorms were discussed. The following presents an overview of the five IN schemes proposed to be simulated and the applicable conditions. 


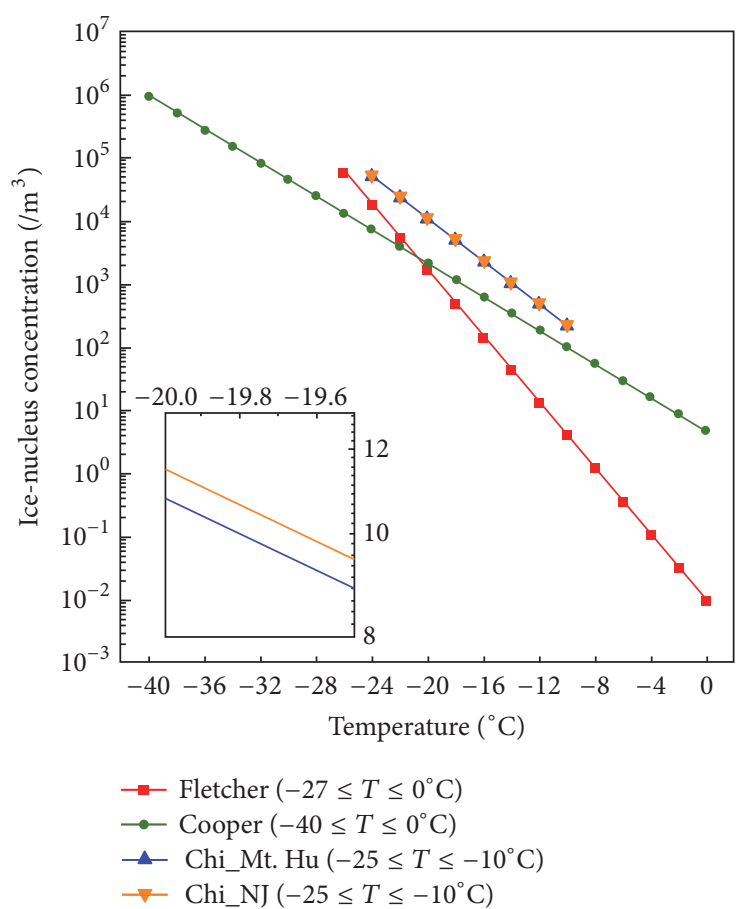

(a)

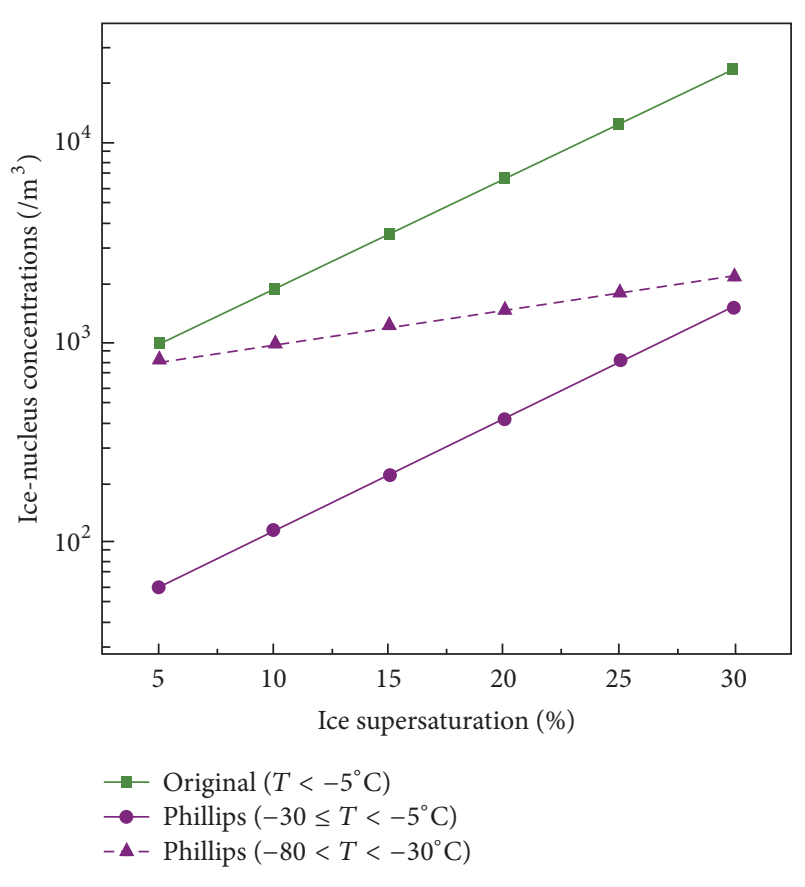

(b)

Figure 1: Variation of the ice nuclei concentration (unit: $\mathrm{L}^{-1}$ ) depending on the activation temperature; (a) $T 1$ and $T 2$ groups (unit: ${ }^{\circ} \mathrm{C}$ ) and ice surface supersaturation; (b) $S$ group (unit: \%).

(1) The Fletcher [13] Scheme

$$
N_{i}=10^{-5} \times \exp (-0.6 \times T) .
$$

The parameter $N_{i}$ is the number of activated IN in the unit volume $\left(\mathrm{L}^{-1}\right), T$ is the corresponding temperature when the IN is activated, and the applicable temperature ranges from $-27^{\circ} \mathrm{C}$ to $0^{\circ} \mathrm{C}$. The concentration of IN calculated by this scheme is lower than the value observed at higher temperatures and the calculated concentration is higher when the temperature is relatively low $\left(-25^{\circ} \mathrm{C}\right)$.

\section{(2) The Cooper [15] Scheme}

$$
N_{i}=0.005 \times \exp (-0.304 \times T) .
$$

The applicable temperature ranges from $-40^{\circ} \mathrm{C}$ to $0^{\circ} \mathrm{C}$.

(3) The Phillips et al. [39] Scheme. Phillips et al. [39] integrated and improved the Meyers [11] and DeMott schemes [38]. The empirical correction factor $\Psi$ was added and the applicable temperature range of ice nucleation activation was extended:

$$
\begin{aligned}
& N_{i} \\
& = \begin{cases}\exp \left[-0.639+12.96\left(S_{i}-1\right)\right] \times \Psi, & -30 \leq T<-5 \\
\left\{\exp \left[12.96\left(S_{i}-1.1\right)\right]\right\}^{0.3}, & -80<T<-30,\end{cases}
\end{aligned}
$$

where the empirical correction factor $\Psi=0.06$ and $S_{i}$ represents the surface saturation relative to ice.
(4) The Huang Mountain Observation (Chi_Mt. H) Scheme [40]. As differences in the IN concentration are significant due to the influence of regional and meteorological factors, the empirical relationship of the Chinese IN observation was introduced. Su [40] observed IN at the top of the Huang Mountain in Anhui, China, using a $5 \mathrm{~L}$ Bigg mixing cloud chamber. The observation period was May to October 2011 and the total IN concentration equation (temperature range from $-25^{\circ} \mathrm{C}$ to $-10^{\circ} \mathrm{C}$ ) was developed by fitting, considering four types of nucleation mechanisms (deposition, condensation-freezing, contact-freezing, and immersionfreezing):

$$
N_{i}=0.0046 \times \exp (-0.388 \times T) .
$$

(5) The Nanjing Observation (Chi_NJ) Scheme [41]. Yang et al. [41] performed observations using a $5 \mathrm{~L}$ Bigg mixed cloud chamber in Nanjing, China. The observation period was summer 2011 and a total ice nucleation concentration equation (temperature ranging from $-25^{\circ} \mathrm{C}$ to $-10^{\circ} \mathrm{C}$ ) based on the four nucleation mechanisms was developed:

$$
N_{i}=0.0049 \times \exp (-0.388 \times T) .
$$

To understand the microphysical characteristics of clouds and the response of precipitation to variations in the IN concentration, the six ice nucleation schemes were divided into three groups according to the calculation method of the IN concentration (Figure 1) and the temporal and spatial hydrometeor evolution were compared. 


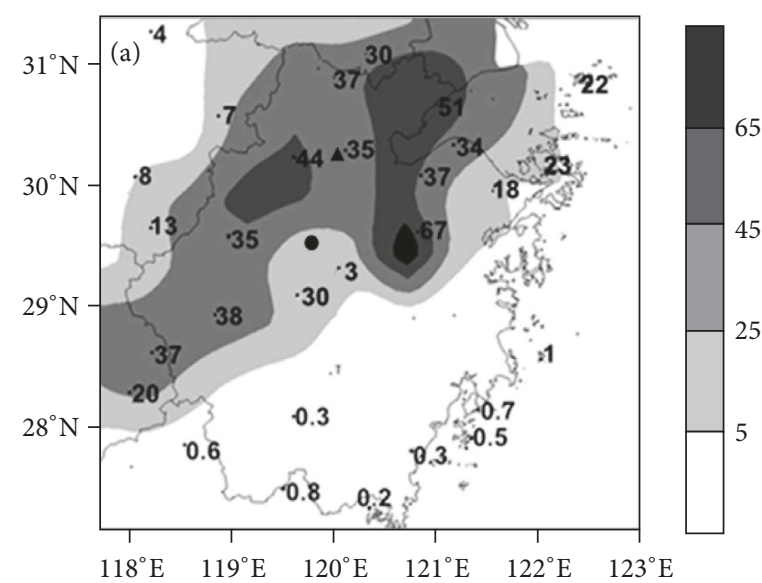

(a)

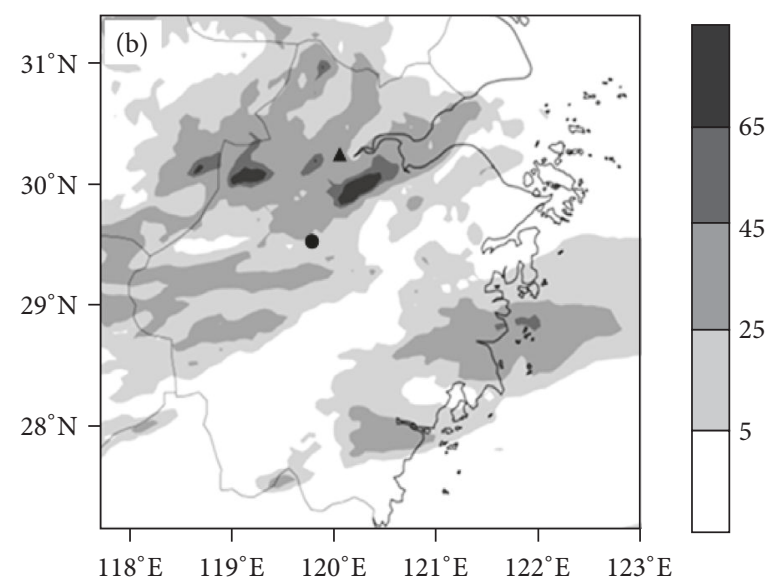

(b)

FIGURE 2: Six-hour cumulative precipitation in Zhejiang at 20:00 CST on November 9; (a) observed and (b) simulated (unit: mm). The black dot represents the Pujiang area and the black triangle represents the Hangzhou area.

In the first group, the IN concentration is temperaturedependent, which is the classical fit ( $T 1$ group) suitable for the deposition and condensation-freezing nucleation processes including the Fletcher and Cooper schemes. The second group is also temperature-dependent (mixed-phase cloud chamber measurements in China). It refers to the total IN concentration equation based on all nucleation mechanisms (T2 group) including the Chi_NJ and Chi_Mt. H schemes. The third group is related to the supersaturation relative to the ice surface ( $S$ group) and includes the Philips and original Meyers schemes.

\section{Analysis of Numerical Simulation Results}

4.1. Simulation and Analysis of Ground Rainfall. The main precipitation area of this severe convective weather process is northern and western Zhejiang Province and the rainfall belt follows a northeast-southwest direction. The six hours of cumulative precipitation, beginning at 9:00 CST on November 9 , reached $67 \mathrm{~mm}$ (Figure 2(a)). A secondary precipitation center was located in the Hangzhou area, where the cumulative rainfall reached $44 \mathrm{~mm}$. The precipitation area and time of occurrence of the simulated 6-h cumulative precipitation (Figure 2(b)) were close to the actual condition. The precipitation can be divided into two northeastern-southwestern rain belts located in central-northern and southeastern Zhejiang. The northern precipitation belt was close to the actual situation and the location of the precipitation center was consistent. The maximum cumulative rainfall was $70 \mathrm{~mm}$, close to that observed. The cumulative precipitation of the largest precipitation center in Hangzhou was $70 \mathrm{~mm}$, which was higher than that observed.

4.2. Characteristics and Simulation of Radar Echo Evolution. In this paper, the S-band of the newly generated Doppler weather radar (CINRAD/SA) data from the Hangzhou Station was used. At 11:43 CST on November 9, a convection storm cell formed in the Huangshan area. At 12:17 CST, the convection cell moved northeast and the intensity reached
$65 \mathrm{dBz}$ (Figure 3). Subsequently, this strong convective cloud continued to move eastwards while merging with cells in the front and strengthening. At 13:42 CST, a multicellular storm composed of convection cells at different development stages formed in the Hangzhou area. It was hook-shaped and the echo top was $11 \mathrm{~km}$ high. At 15:23 CST, the multicellular storm continued to develop and new cells were constantly generated to the northeast and merged into the storm. Ultimately, a vault convection belt was formed in Hangzhou and strong thunderstorms and winds occurred in the Hangzhou area. In the Pujiang County area at the southern end of the echo zone, another strong convection cell developed and moved eastwards with an intensity reaching $65 \mathrm{dBz}$. The top of the echo was $16 \mathrm{~km}$ and the convection was strong. At approximately 15:45 CST, ground hail occurred in Pujiang. At 17:42 CST, the multicellular storm scattered into several strong convection cells with wide coverage and formed a bow echo. Its intensity was $60 \mathrm{dBz}$, and the maximum height of the echo reached $14 \mathrm{~km}$, corresponding to the thunderstorm weather occurring at 18:00 CST. Subsequently, the echo belt weakened and moved eastwards into the sea, ending the strong convective weather in the Zhejiang Province.

The simulated precipitation area and intensity of the maximum echo are consistent with the observation; both showed eastward movement, which clearly indicates the evolution characteristics of the strong convection cell such as formation, development, and mature stages. Slight differences of the observation are a larger echo range and slower simulated development speed of the multicellular storm. The simulations lagged behind the actual storm by approximately one hour.

\section{Comparative Experiment on the Effect of Ice Nuclei Parameterizations on the Convective Precipitation Process}

5.1. Comparison of Cumulative Ground Rainfall. Figure 4 shows the simulated 6 -h cumulative ground precipitation at 

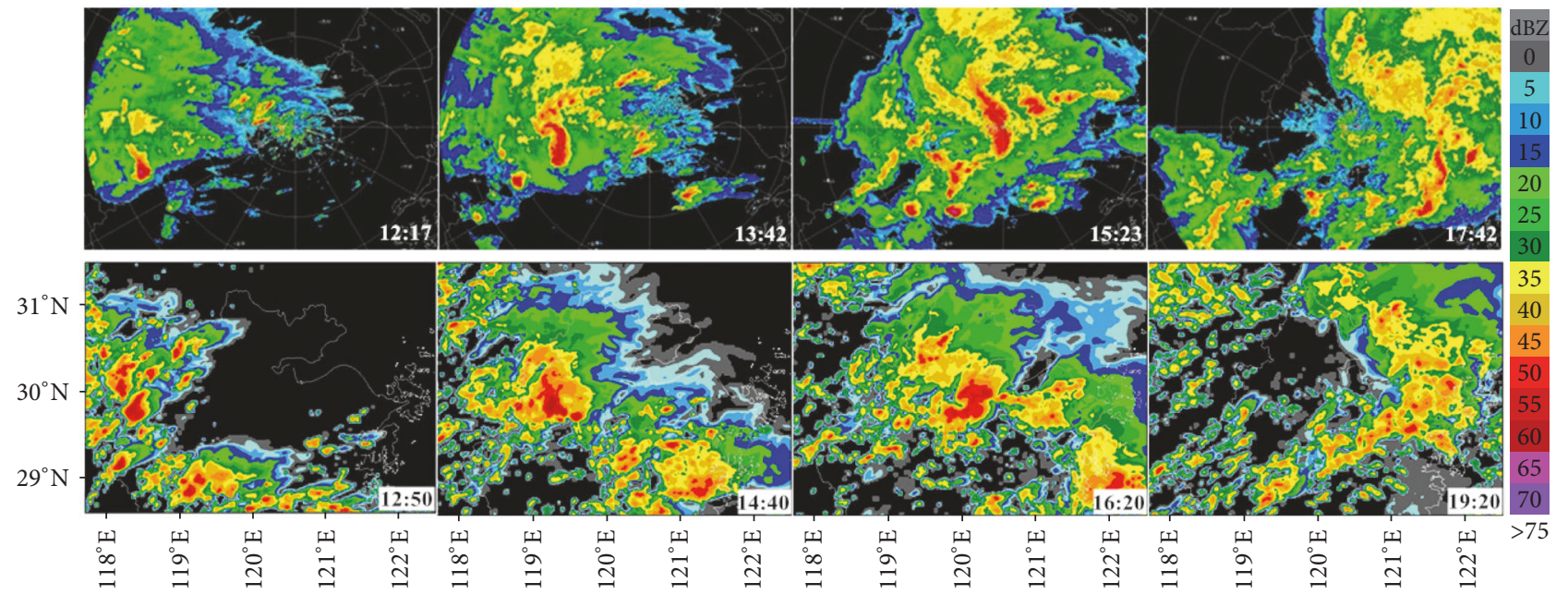

FIGURE 3: Comparison of the radar reflectivity factor (top) between 12:00 and 18:00 CST on November 9 and the simulated maximum reflectivity (bottom; unit: $\mathrm{dBz}$ ).
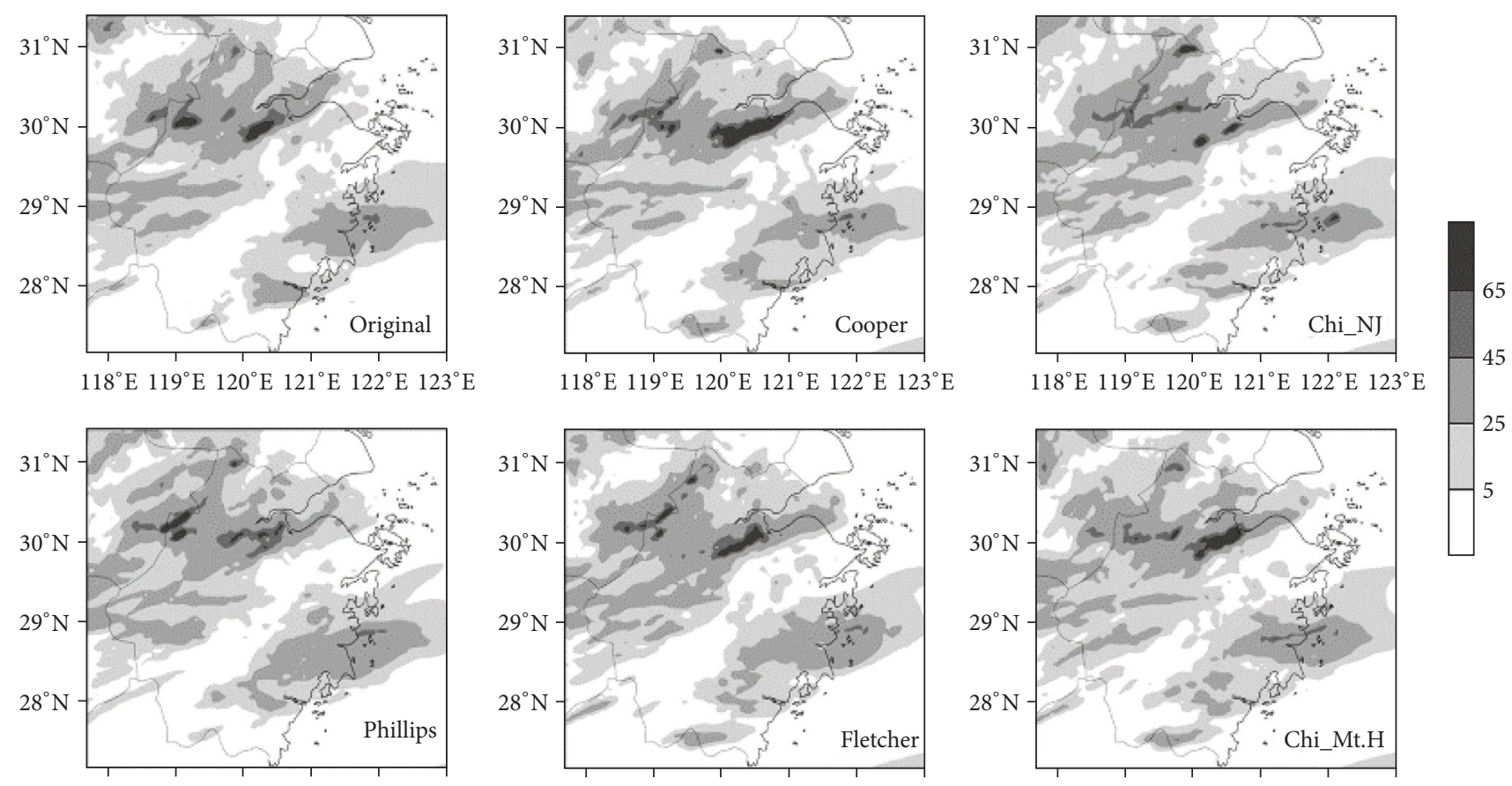

$118^{\circ} \mathrm{E} 119^{\circ} \mathrm{E} 120^{\circ} \mathrm{E} 121^{\circ} \mathrm{E} 122^{\circ} \mathrm{E} 123^{\circ} \mathrm{E}$

$118^{\circ} \mathrm{E} 119^{\circ} \mathrm{E} 120^{\circ} \mathrm{E} 121^{\circ} \mathrm{E} 122^{\circ} \mathrm{E} 123^{\circ} \mathrm{E}$

$118^{\circ} \mathrm{E} 119^{\circ} \mathrm{E} 120^{\circ} \mathrm{E} 121^{\circ} \mathrm{E} 122^{\circ} \mathrm{E} 123^{\circ} \mathrm{E}$

FIGURE 4: Simulation of the 6-h cumulative precipitation at 20:00 CST on November 9 in the Zhejiang Province based on different ice nuclei parameterizations (unit: $\mathrm{mm}$ ).

20:00 CST on November 9 based on the six IN parameterizations. Compared with the observed precipitation (Figure 2(a)), all parameterizations simulated the trends and range of rainfall, but the rainfall intensity and heavy rainfall center of the rain belt were different. For the heavy rainfall centers, the results of the Fletcher, Chi_Mt. H, and original schemes were the closest to the actual situation and the intensities were greater than $65 \mathrm{~mm}$. In addition, the rainfall intensity predicted by the Chi_NJ program was smaller, while that by the Cooper scheme was larger. For the secondary precipitation center in Hangzhou, the intensity and location simulated with the Fletcher, Philips, and original schemes were the most accurate. Overall, the Fletcher scheme was closest to the actual situation (followed by the original scheme) in terms of the simulated range, trend, and rainfall intensity of the rain belt and the locations of the two precipitation centers matched the actual locations.

5.2. Comparative Analysis of Ground Cumulative Hailfall. According to the cumulative hailfall intensity and distribution, the simulation results of the Cooper scheme (Figure 5) were the least accurate and the center position of the strongest 

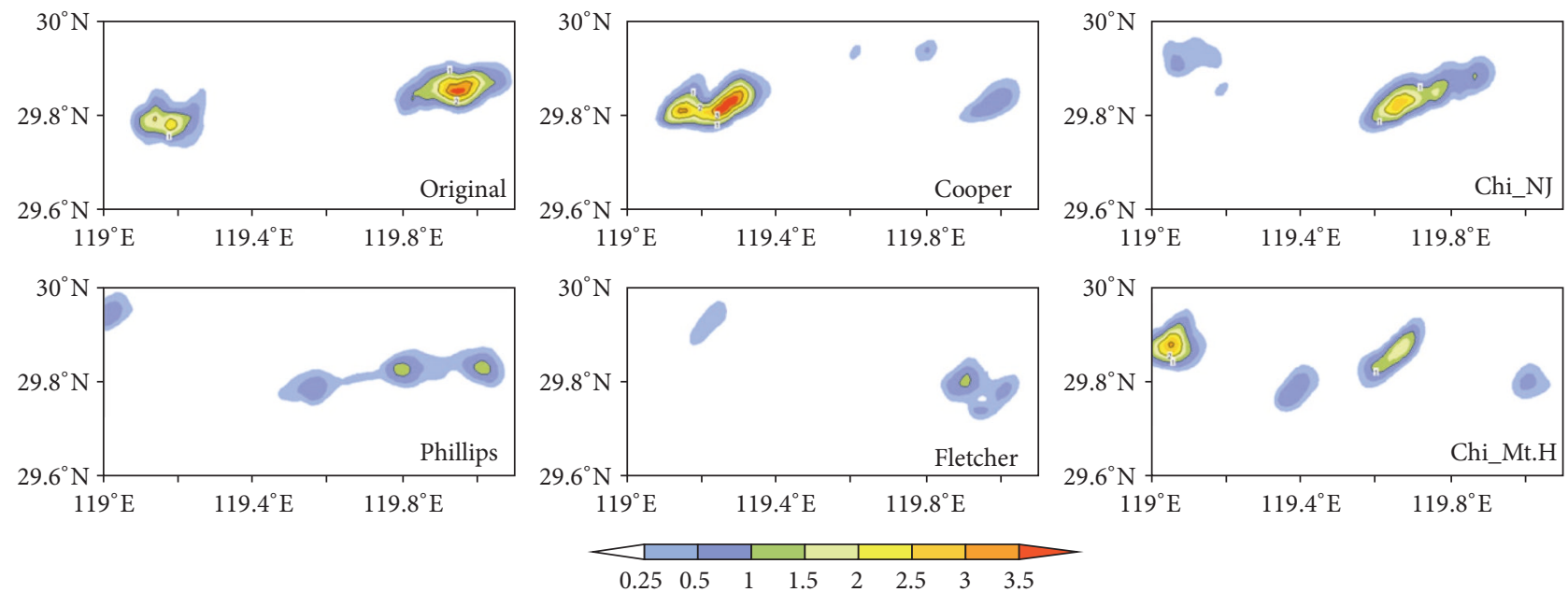

FIGURE 5: Case study 09: Simulated ground cumulative hail volume in the Pujiang area at 17:00 CST based on different simulations (unit: $\mathrm{mm})$.

hailfall deviated to the west of Pujiang. The hail intensity in Pujiang was the smallest with respect to the other five schemes. The Chi_Mt. H scheme simulation results were also not ideal, showing a deviation in the location of maximum hailfall. The maximum hailfall locations simulated by the other schemes appeared in the Pujiang area. The original scheme showed the highest hail amount, while the Fletcher scheme showed the smallest.

In summary, the effect of the IN concentration on ground hail is significantly stronger than that on ground rainfall. The IN influences the formation and growth of large ice particles by changing the ice crystals, which directly contributes to ground hail. For rainfall, only the strong precipitation center location and rainfall amount differ slightly; the difference does not exceed $5 \mathrm{~mm}$.

\subsection{Influence of Ice Nuclei Parameterizations on the Microphysical Structure of Convective Clouds}

5.3.1. Influence on the Spatial and Temporal Distribution of Initial Ice Crystals. Figure 6 shows that the variation of the IN concentration directly affects the spatiotemporal distribution of the initial ice crystals (Figures 6(a) and 6(b)). The ice crystals generated in the hail cloud formation period are used as initial ice crystals and the average ice crystal water content and number concentration characteristics (Figures 6(a) and 6(b)) and vertical distributions of ice crystal water content (Figure 7) were analyzed. The results show that the average ice water content and number concentrations during the period before 14:00 CST are as follows: (1) T1 group: Cooper > Fletcher; (2) T2 group: Chi_NJ > Chi_Mt. H; and (3) $S$ group: the original program $>$ Philips. Based on the combination with the IN concentration (Figure 1), the distribution of ice crystals is related to the IN distribution. A greater number of IN leads to a greater number of initial ice crystals with higher water content. For example, the applicable temperature range (from $-40^{\circ} \mathrm{C}$ to $0^{\circ} \mathrm{C}$ ) of ice nucleation activation in the Cooper scheme is the largest. The IN concentration increased rapidly with a decrease of temperature and therefore the highest concentration of initial ice crystals was produced $\left(110 \times 10^{3} \mathrm{~L}^{-1}\right)$ and the water content was the highest $\left(21 \mathrm{mg} \cdot \mathrm{kg}^{-1}\right)$. In comparison, the IN concentration of the Fletcher scheme was the smallest and the applicable temperature range was smaller than that of the Cooper scheme. Therefore, the number of initial ice crystals in this scheme was the smallest $\left(51 \times 10^{3} \mathrm{~L}^{-1}\right)$ and the water content was the lowest $\left(13 \mathrm{mg} \cdot \mathrm{kg}^{-1}\right)$. The differences in the concentration and water content of ice crystals between these two schemes were $59 \times 10^{3} \mathrm{~L}^{-1}$ and $8 \mathrm{mg} \cdot \mathrm{kg}^{-1}$, respectively.

5.3.2. Influence on the Vertical Distribution of Ice Crystals. The differences in the vertical distribution of ice crystals in each scheme are due to the maximum values and water content (Figure 6(c)). The Cooper scheme has the highest height of maximum value and water content of ice crystal. The Fletcher scheme has the lowest height of maximum value $(8.5 \mathrm{~km})$ and water content of ice crystal. This difference is due to the Cooper scheme having a wider temperature range; there are more IN at lower temperatures and, in contrast, less IN in the low temperature ranges in the Fletcher scheme. Thus, the height at which ice crystals are present is related to the temperature range of ice nucleation activation.

\subsubsection{Effects of Different Ice Nuclei Parameterizations on the} Spatial and Temporal Distribution of Other Hydrometeors. The variation of the IN concentration leads to different changes of different types of hydrometeors. Ice crystals, as the most basic ice-phase particles, change the temporal and spatial distribution of other hydrometeors and the macrodevelopment and structure of the cloud by participating in the ice-phase transformation process. On the other hand, these changes will in turn affect the temporal and spatial distribution of ice crystals through microphysical processes. To understand the evolution of microphysical processes in the cloud, the spatiotemporal distributions of the airflow structure and hydrometeors in the cloud are analyzed in detail. 


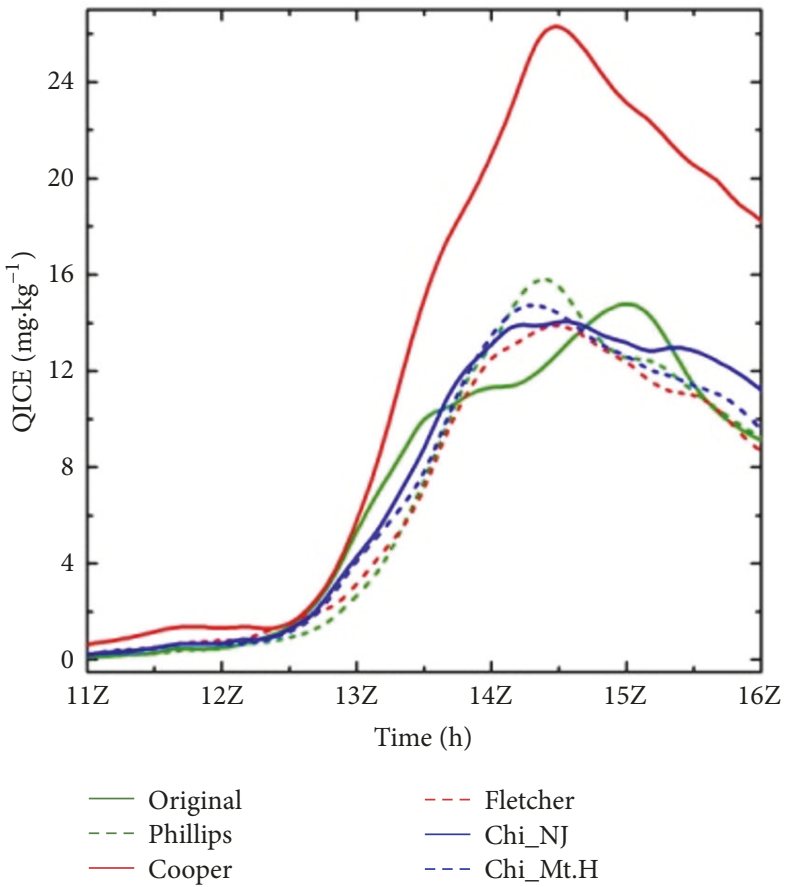

(a)

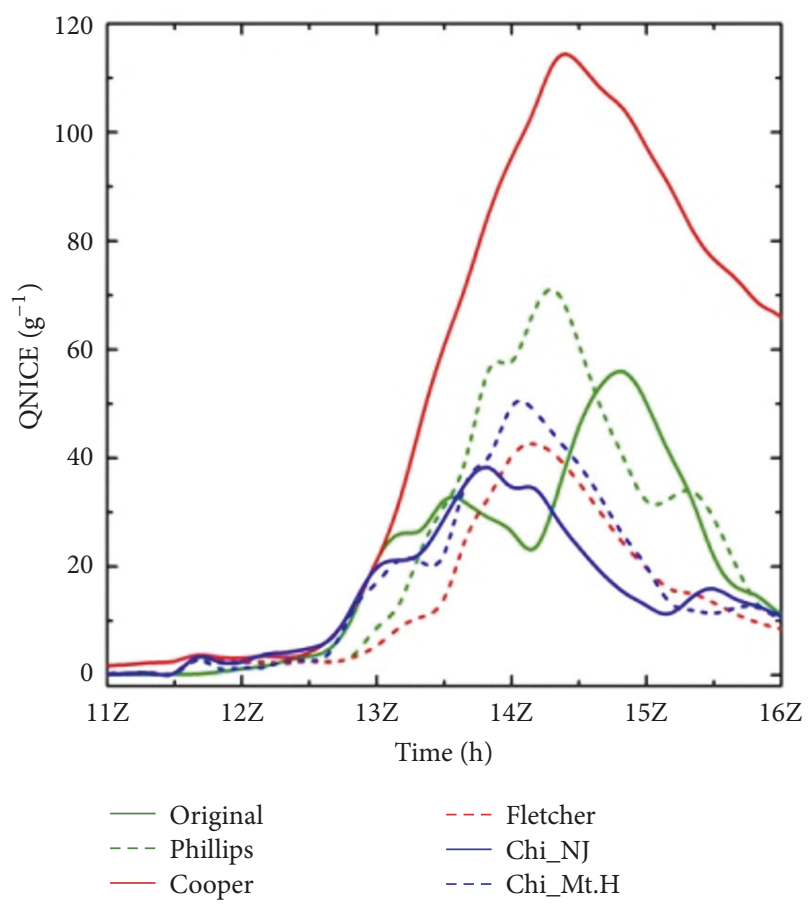

(b)

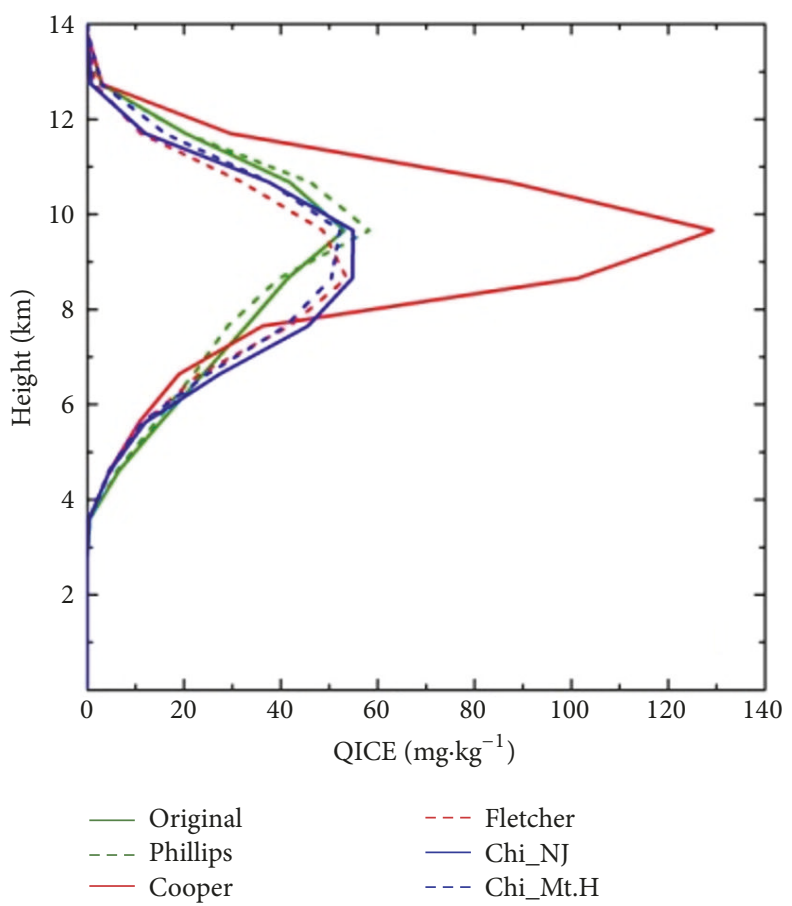

(c)

FIGURE 6: Variation of the regional $\left(118.7^{\circ} \mathrm{E}-120.2^{\circ} \mathrm{E}, 29.4^{\circ} \mathrm{N}-30.4^{\circ} \mathrm{N}\right)$ average mixing ratio ((a) unit: $\left.\mathrm{mg} \cdot \mathrm{kg}^{-1}\right)$ and the number concentrations ((b) unit: $\left.10^{3} \mathrm{~L}^{-1}\right)$ of ice crystals with time and the variation of the regional average mixing ratio with height from the hail cloud generation to the extinction period ((c) unit: $\left.\mathrm{mg} \cdot \mathrm{kg}^{-1}\right)$.

(1) Influence on the Temporal and Spatial Distribution of Snow Particles. In combination with the temporal evolution of ice crystals, the macroscopic variation of the snow water content over time was analyzed (Figure 8). The peak of snow water occurs slightly later than the peak of ice crystals. The lag of snow water indicates that initial ice crystals were formed first 

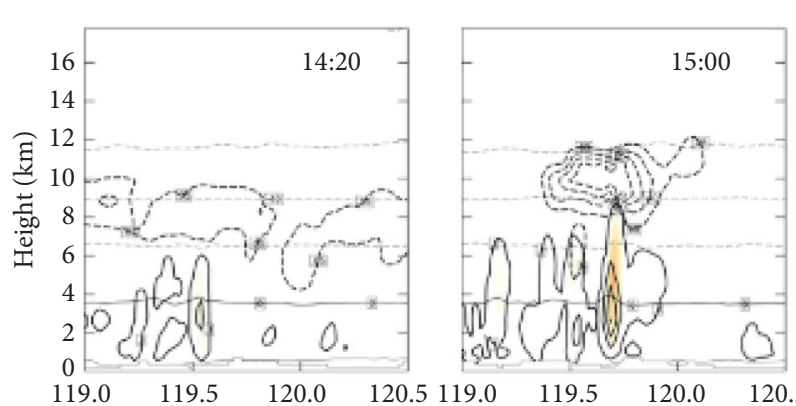

$S$
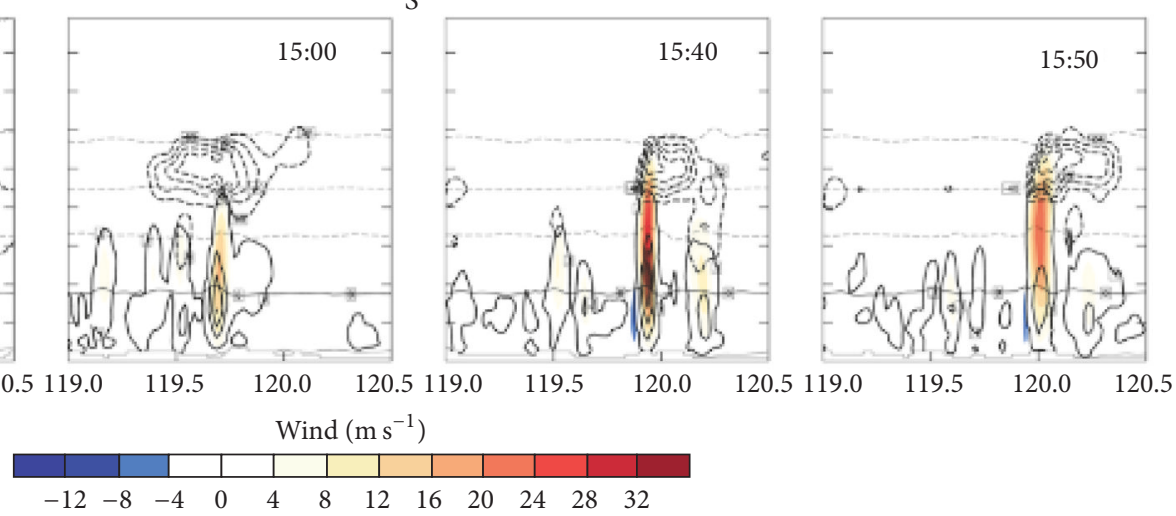

(a)

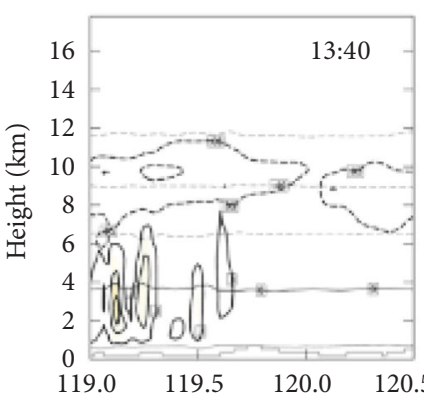

$S$
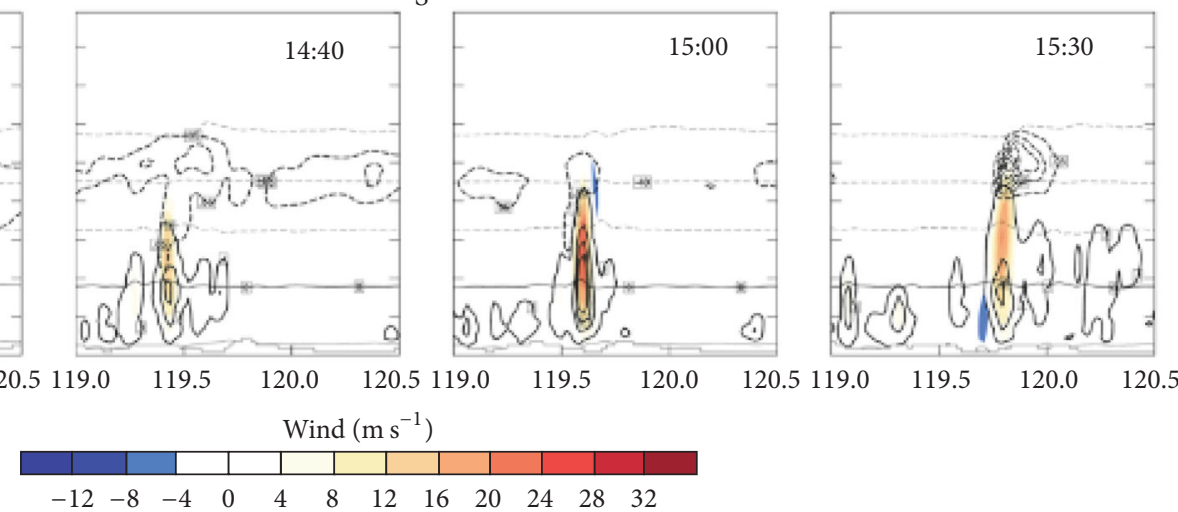

(b)

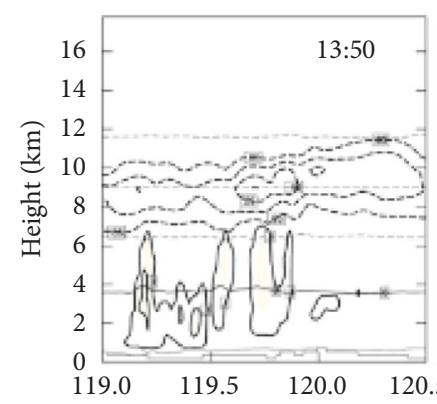

$T 1$
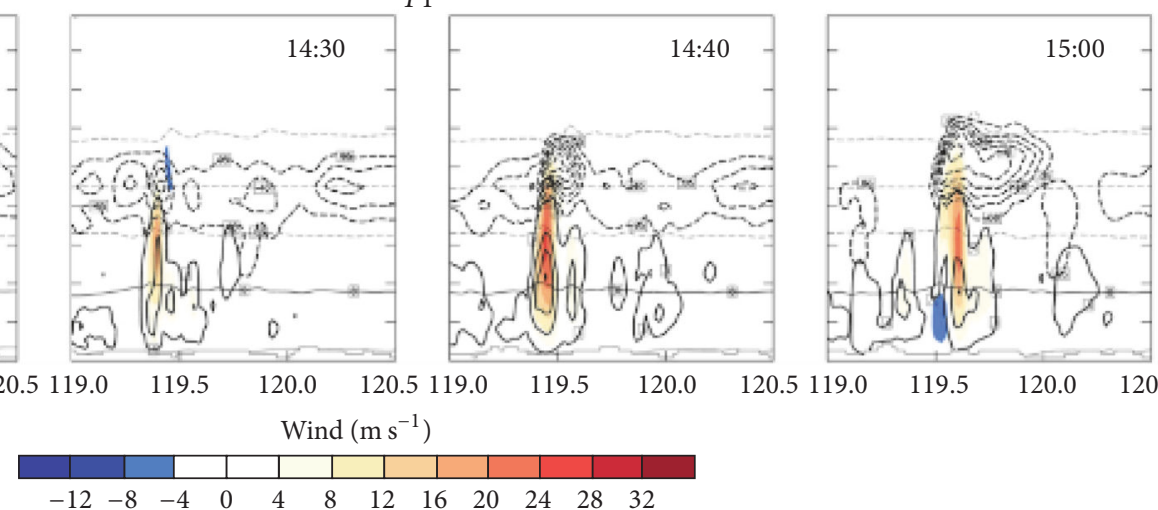

(c)
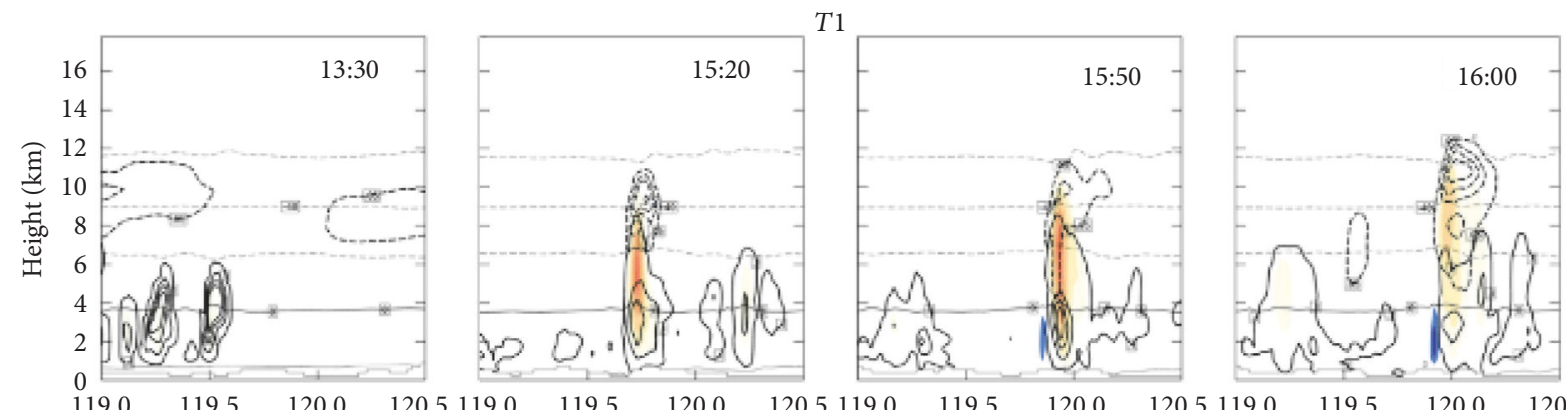

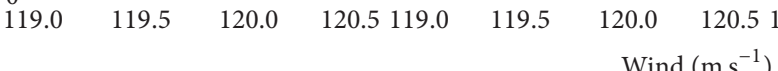

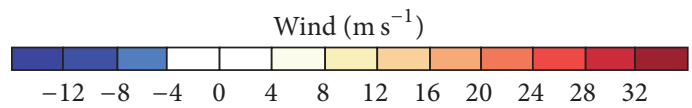

(d)

Figure 7: Continued. 


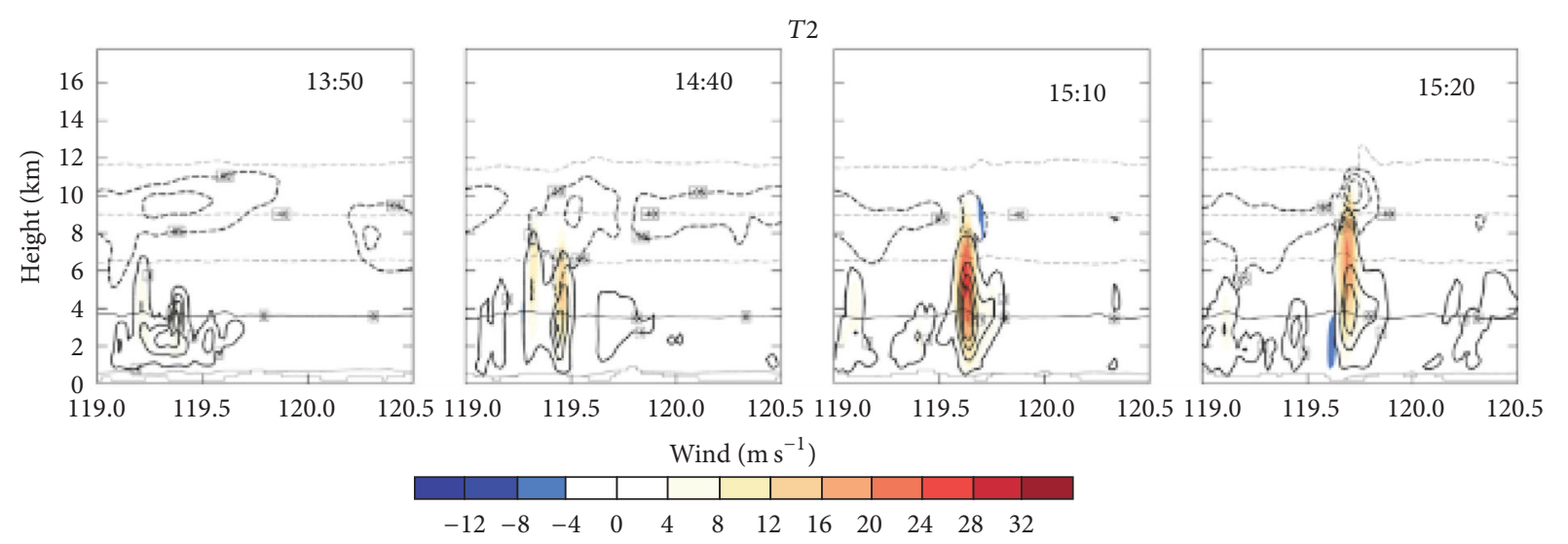

(e)
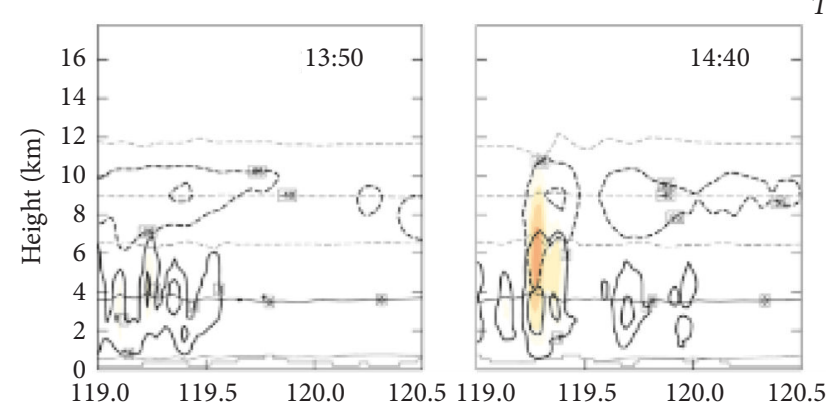

2
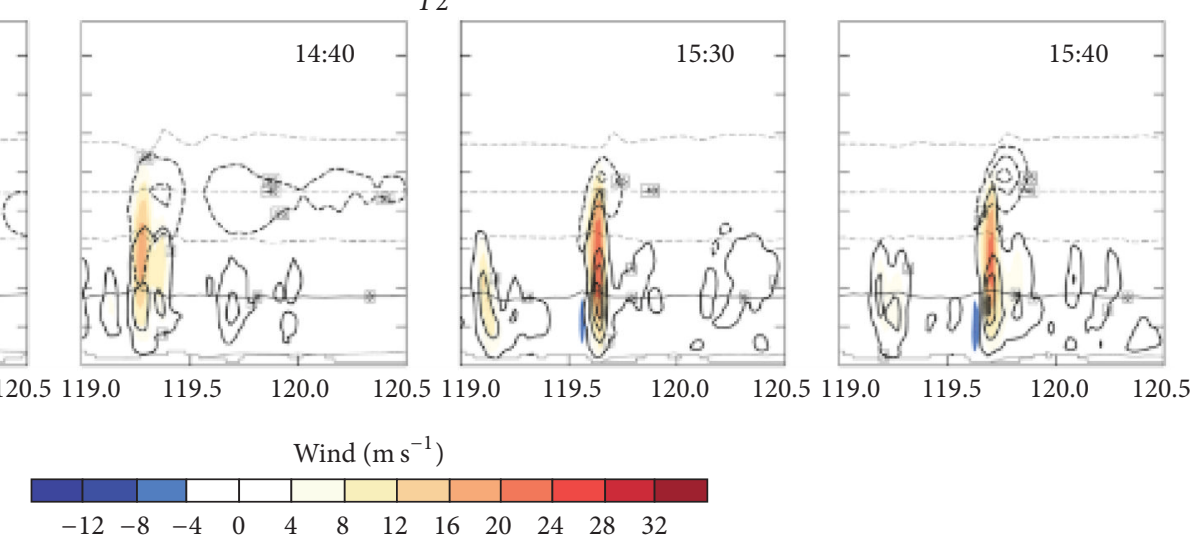

(f)

FIGURE 7: Cross section of the simulated cloud water mixing ratio (solid line, minimum $0.1 \mathrm{~g} \cdot \mathrm{kg}^{-1}$, interval $1 \mathrm{~g} \cdot \mathrm{kg}^{-1}$ ), ice crystal mixing ratio (black dotted line, minimum $0.05 \mathrm{~g} \cdot \mathrm{kg}^{-1}$, interval $0.1 \mathrm{~g} \cdot \mathrm{kg}^{-1}$ ), and updraft (colored) and isothermal line (dashed gray line) in latitudinal direction: (a) original; (b) Philips; (c) Cooper; (d) Fletcher; (e) Chi_NJ; and (f) Chi_Mt.H.

and then grew to a certain size through deposition, Bergeron, and collision processes and eventually transformed into snow particles.

The spatial distribution characteristics of snow particles at different stages were analyzed (Figure 9). In the developing and early-mature stages of hail cloud, the snow water content is in the following order: (1) T1 group: Cooper < Fletcher; (2) T2 group: Chi_NJ < Chi_Mt. H; and (3) $S$ group: original $<$ Philips. This is opposite to the distribution of the ice crystal content in the previous section. The distribution and variation characteristics of the concentration of snow particles are similar to those of the water content (Figure 8(b)).

The above-mentioned results show that the increase of ice crystal caused by increased IN is not conducive to the formation and growth of snow particles. In case of a constant amount of water vapor, the water vapor consumption increases with increasing formation of ice crystals. Many ice crystals compete for limited water vapor and cannot grow quickly to transform into snow crystals, thus inhibiting the production and growth of snow particles, resulting in a lower amount of snow particles.
(2) Influence on the Temporal and Spatial Distribution of Cloud Water and Rainwater. The modified IN parameterization schemes have the least effect on the cloud water and rainwater content. The cloud water content (Figure 7) during the initial stage is in the order of original program $<$ Philips and Cooper $<$ Fletcher because a greater number of IN eventually result in an increased number of ice crystals, thus raising the consumption of liquid water in the cloud.

With respect to the rainwater content (Figure 9), schemes with more IN correspond to less rainwater below the $0^{\circ} \mathrm{C}$ level before the maturation stage (e.g., Chi_NJ < Chi_Mt. H). As the IN concentration increases, many ice crystals compete for liquid water, consequently inhibiting the growth of ice particles. This is not conducive to the growth of large-sized ice particles and formation of raindrops and results in less rain. In addition, the increased intensity of the updraft in the cloud leads to a reduced liquid water content below the $0^{\circ} \mathrm{C}$ layer. However, this trend is less pronounced after the maturation of the hail cloud.

(3) Influence on the Spatial and Temporal Distribution of Hail Embryos (Graupel) and Hail. The relationship between ice 


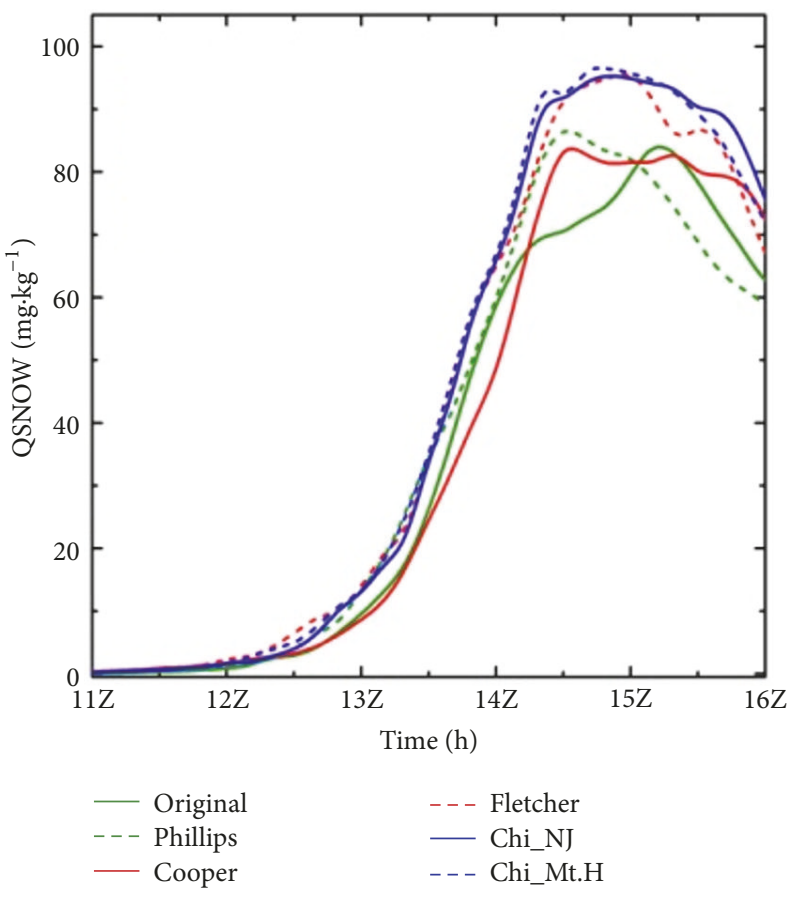

(a)

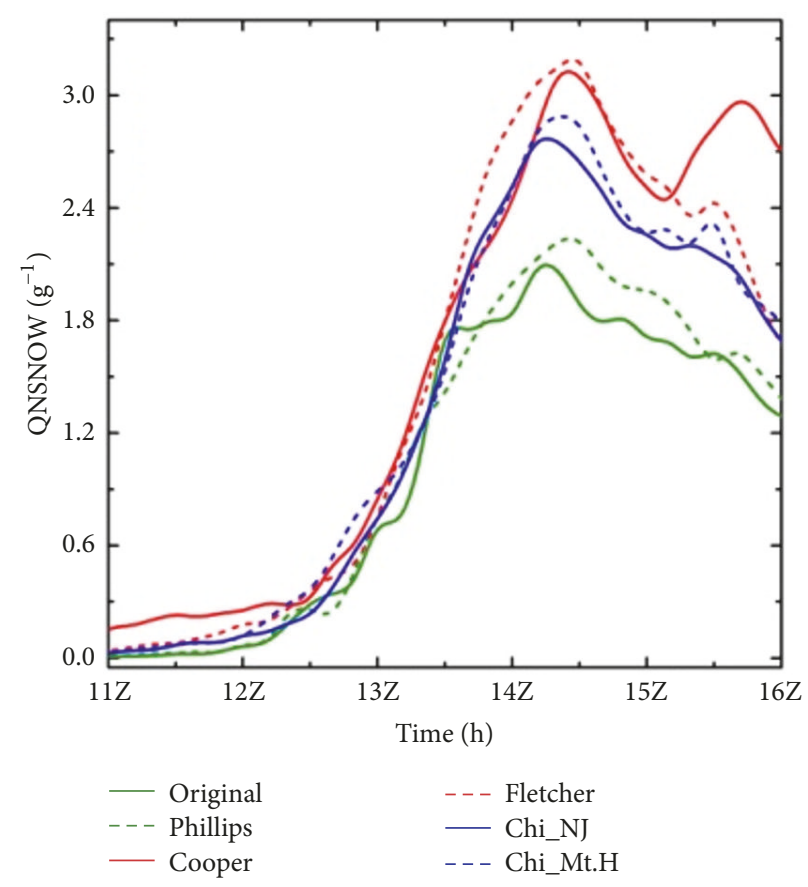

(b)

Figure 8: Variation of the regional average $\left(118.7^{\circ} \mathrm{E}-120.2^{\circ} \mathrm{E}, 29.4^{\circ} \mathrm{N}-30.4^{\circ} \mathrm{N}\right)$ mixing ratio ((a) unit: $\left.\mathrm{mg} \cdot \mathrm{kg}^{-1}\right)$ and concentration $((\mathrm{b})$ unit: $10^{3} \mathrm{~L}^{-1}$ ) of snow particles with time.

nuclei and graupel/hail is even more complex. Hail embryos (graupel) formed in the hail cloud developing stage and then enlarged and developed into hail. The hail then grew to a large enough size and started falling in the early-mature stage of the hail cloud. After hail fell on the ground, the hail cloud entered the later maturation stage.

The variation of graupel in each group is similar to that of snow particles from hail embryo formation to hailfall (Figure 10). For example, in the T2 group Chi_NJ < Chi_Mt. $\mathrm{H}$; that is, the graupel water content of the scheme corresponding to more abundant IN is smaller than that of the scheme corresponding to fewer IN. With increasing IN concentration, the early formation of graupel is inhibited and the stronger updraft in the later stages of hail cloud may promote the transformation of snow to graupel particles. As a result, the snow water content in the mature stage is noticeably reduced such as in the Cooper and Chi_NJ schemes (Figure 10).

The hail particles in each group show a variation trend opposite to that of above-mentioned graupel particles in the early or later periods of the mature stage (Figure 11). This is consistent with the results of van den Heever et al. [9] and Carrió et al. [10] who studied the effects of the increase of IN on graupel and hail in a severe precipitation case in Florida. In this study, the hail water content in the $S$ group is in the order of original > Philips scheme in the early stage of hail cloud maturation. In the later maturation stage of the hail cloud, the hail content in the $T 1$ and $T 2$ groups showed the following order: Cooper > Fletcher and Chi_NJ > Chi_Mt. $\mathrm{H}$. The results demonstrate that the scheme with higher IN concentration corresponds to a larger hail water content in the maturation stage and greater amount of hail falling to the ground.

The increase of the IN concentration has a certain inhibitory effect on the growth of hail embryo (graupel; in the development and early maturity stages). However, when hail grew to the hail precipitation stage (later period of the mature stage), the scheme in which the hail content was higher corresponds to a higher IN concentration, indicating that an increased IN concentration is favorable for later hail growth. In the hail embryo formation and growth stages, the increased IN concentration is not conducive to the growth of hail embryos due to reasons similar to those presented for the above-mentioned snow particle suppression; that is, a large number of small ice particles compete for water resources, therefore making it more difficult to grow into large ice particles, leading to lower graupel water contents. More importantly, the amount of snow particles is relatively small. Therefore, the corresponding graupel transformed by snow particle growth decreases. However, at the same time, the intensity of updraft in the cloud increases, which may be due to significant latent heat released by phase transformation (such as deposition, freezing), consequently strengthening the convection in clouds [5, 45].

When graupel grows into hail, the increase in the updraft velocity will transport more supercooled water above the $0^{\circ} \mathrm{C}$ level and lead to the growth of graupel and hail by collision with supercooled water, which is indicated by the apparent supercooled water consumption in the Fletcher scheme (Figure 7). Otherwise, the updraft is strong enough to 

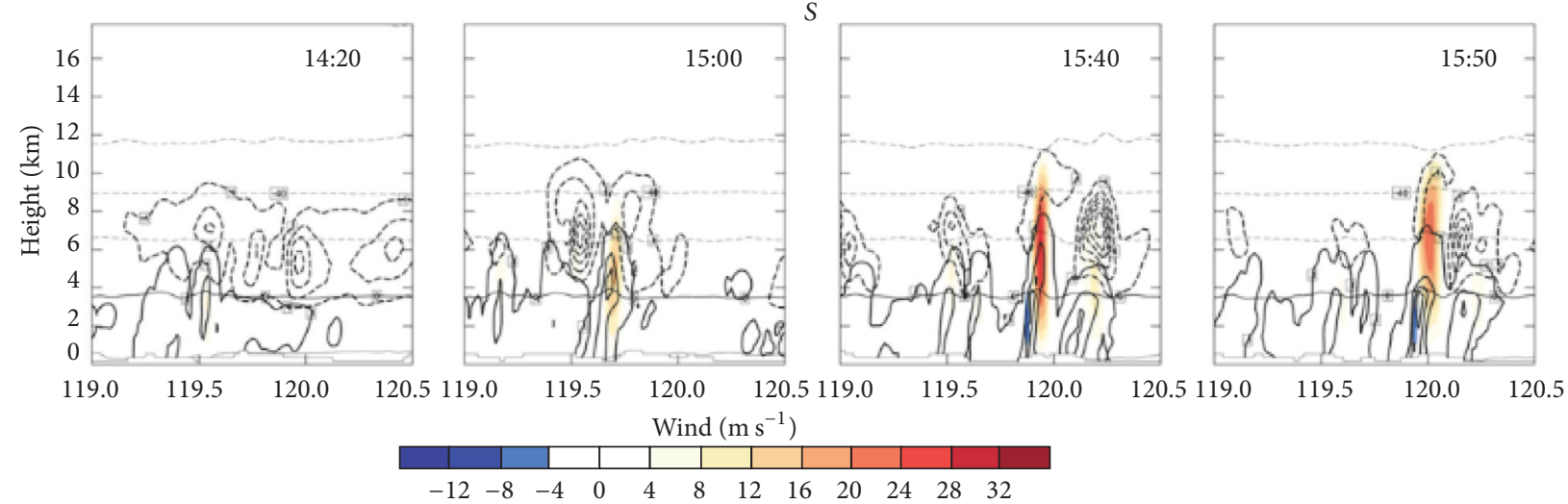

(a)
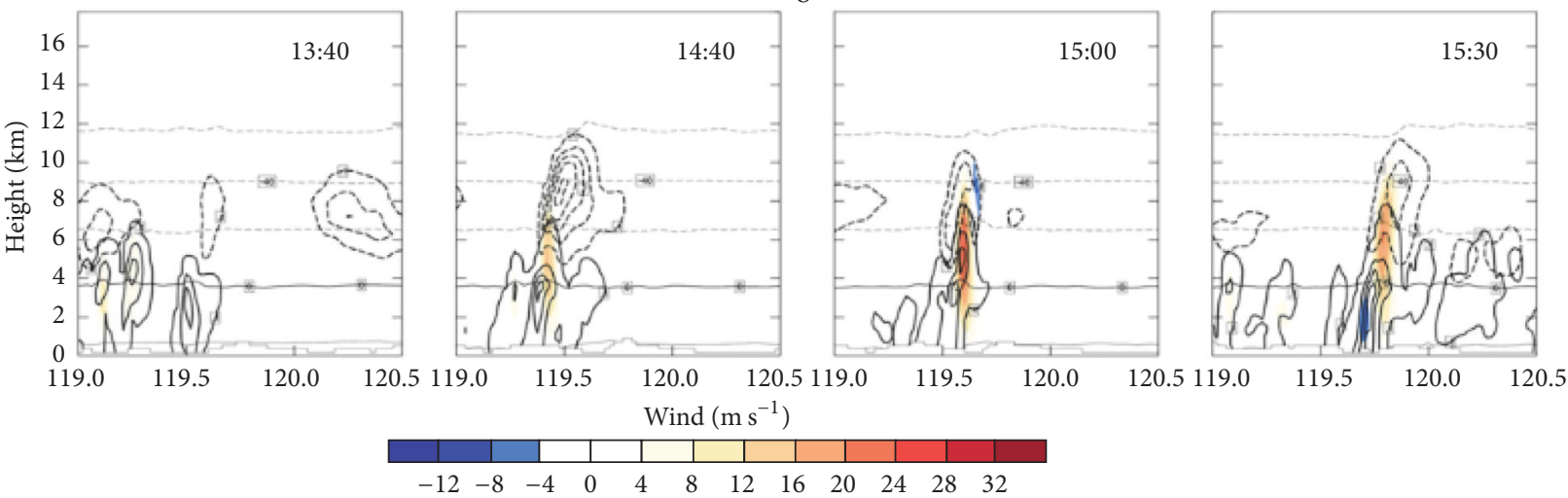

(b)
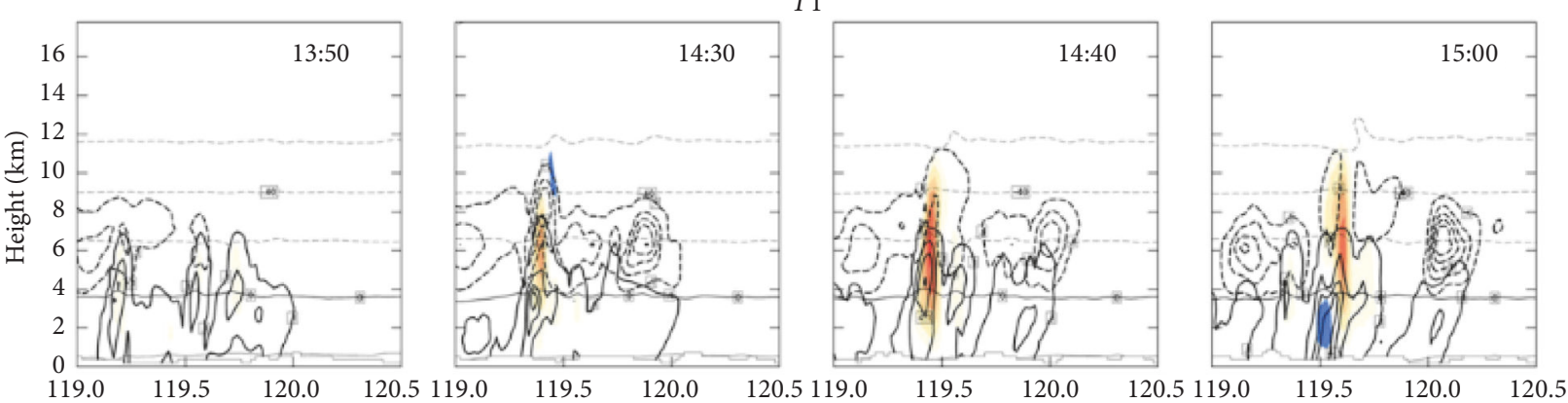

Wind $\left(\mathrm{m} \mathrm{s}^{-1}\right)$

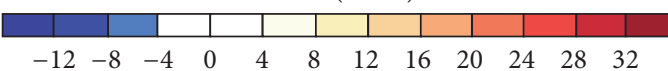

(c)
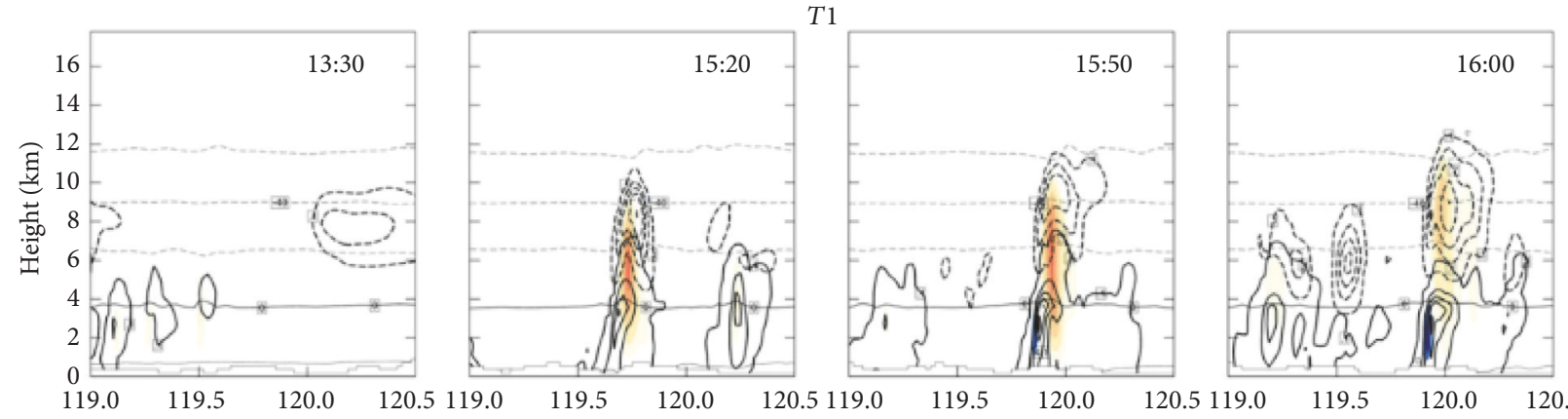

Wind $\left(\mathrm{m} \mathrm{s}^{-1}\right)$

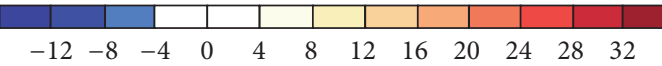

(d)

FIgURE 9: Continued. 


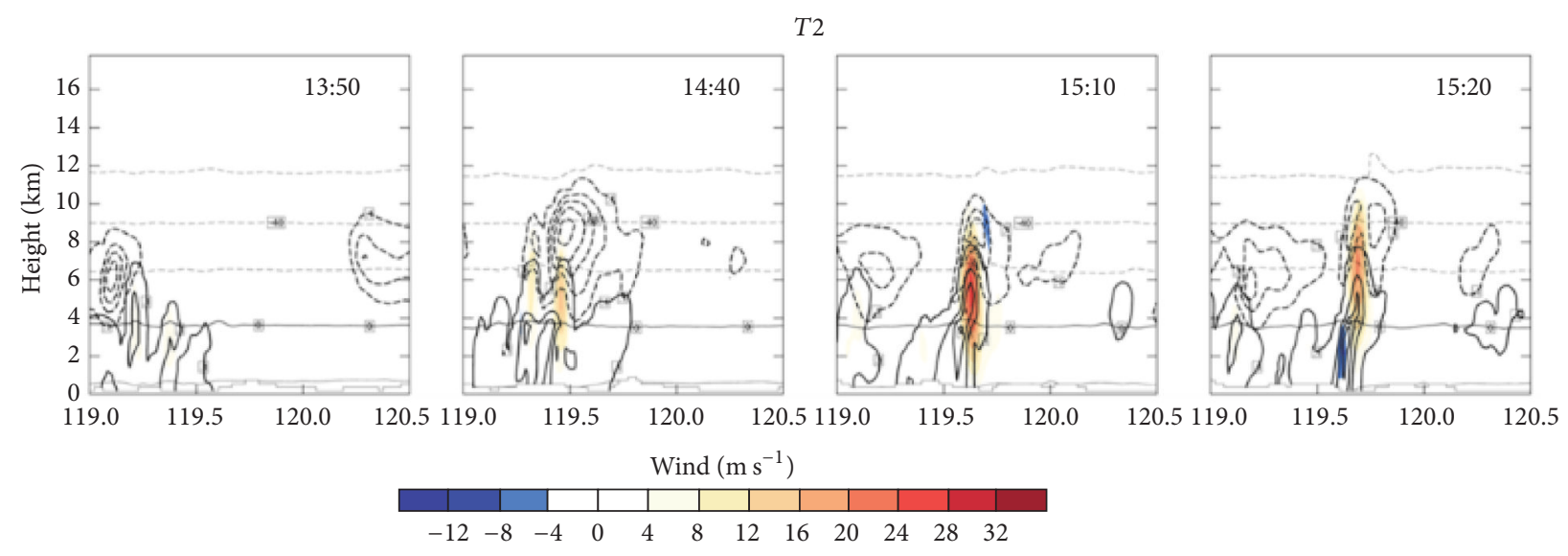

(e)
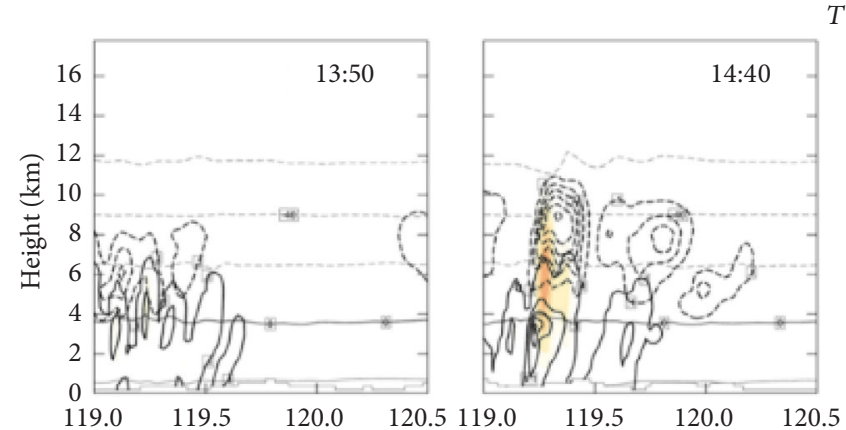

$T 2$

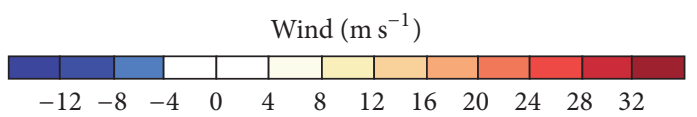

(f)

FIGURE 9: Cross section of the simulated rain water mixing ratio (solid line, minimum $0.1 \mathrm{~g} \cdot \mathrm{kg}^{-1}$, interval $2.5 \mathrm{~g} \cdot \mathrm{kg}^{-1}$ ), snow water mixing ratio (black dotted line, minimum $0.1 \mathrm{~g} \cdot \mathrm{kg}^{-1}$, interval $0.3 \mathrm{~g} \cdot \mathrm{kg}^{-1}$ ), and updraft (colored) and isothermal line (dashed gray line) in latitudinal direction: (a) original; (b) Philips; (c) Cooper; (d) Fletcher; (e) Chi_NJ; and (f) Chi_Mt. H.

allow hail to have more time to encounter supercooled water droplets, allowing hail particles to grow.

\section{Summary and Discussion}

(1) With respect to the hail process simulated in this work, the influence of the IN concentration on ground hailfall is significantly stronger than that on ground rainfall. There were significant differences in hailfall region and intensity. For rainfall, it only led to slightly different locations of the strong precipitation center and rainfall amount and the difference of rainfall did not exceed $5 \mathrm{~mm}$. The changes of the IN concentration caused different changes of hydrometeors in the cloud. The effect on ice crystals was the most significant. The larger the amount of IN is, the greater the initial concentration of ice crystals and water content of ice crystals is. The difference of the ice crystal water content, calculated based on the Cooper scheme with the highest IN concentration and the Fletcher scheme with the smallest IN concentration, was $9 \mathrm{mg} \cdot \mathrm{kg}^{-1}$. The difference in the ice crystal concentration was $95 \times 10^{3} \mathrm{~L}^{-1}$. In addition, the height at which the maximum ice crystal water content occurred was determined by the temperature range of the ice nucleation activation. The effect of the IN concentration on the cloud water and rainwater content was relatively small. As the IN concentration increases, a large number of ice crystals is generated, which compete for water vapor, and the rapid growth of ice crystals through the Bergeron process consumes a large number of supercooled water droplets, which indirectly affects the variation of the cloud water and rainwater content.

(2) In this case, the influence of varying IN concentrations at different stages of the hail cloud also differ. The IN changes the temporal and spatial distribution of other hydrometeors and dynamic structure in the cloud by ice crystal variation. Generally, in the developing and early maturation stages of hail development, a larger number of ice crystals compete for limited water vapor and cloud water as the IN concentration increases, therefore preventing the growth of ice crystals and slowing down their transformation to snow crystals. This indirect dependency has an inhibitory effect on the formation and growth of snow/hail embryos. During the later maturation stage, updraft in the cloud increases, transporting more supercooled water above the $0^{\circ} \mathrm{C}$ level. On the other 

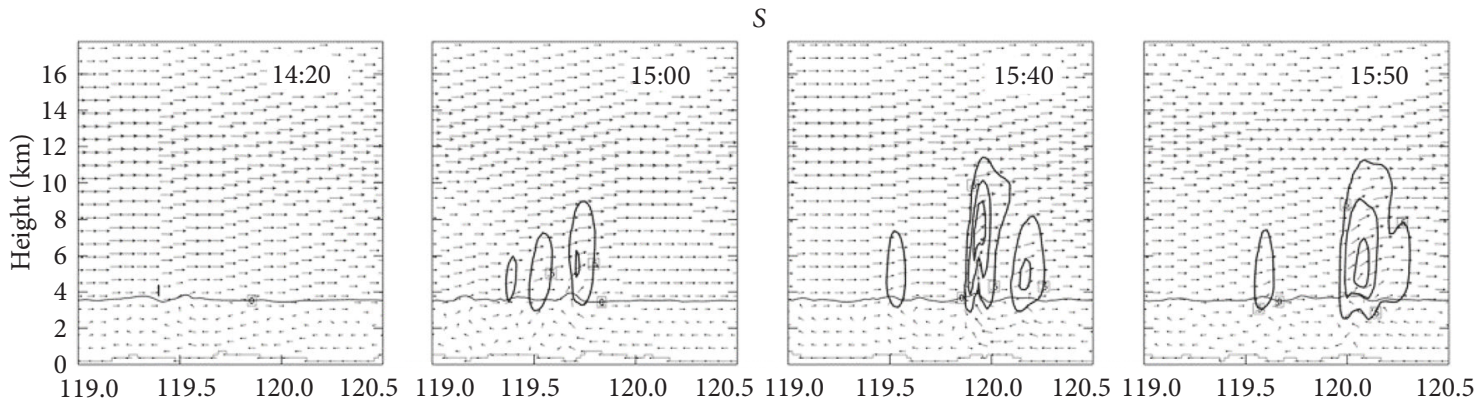

(a)
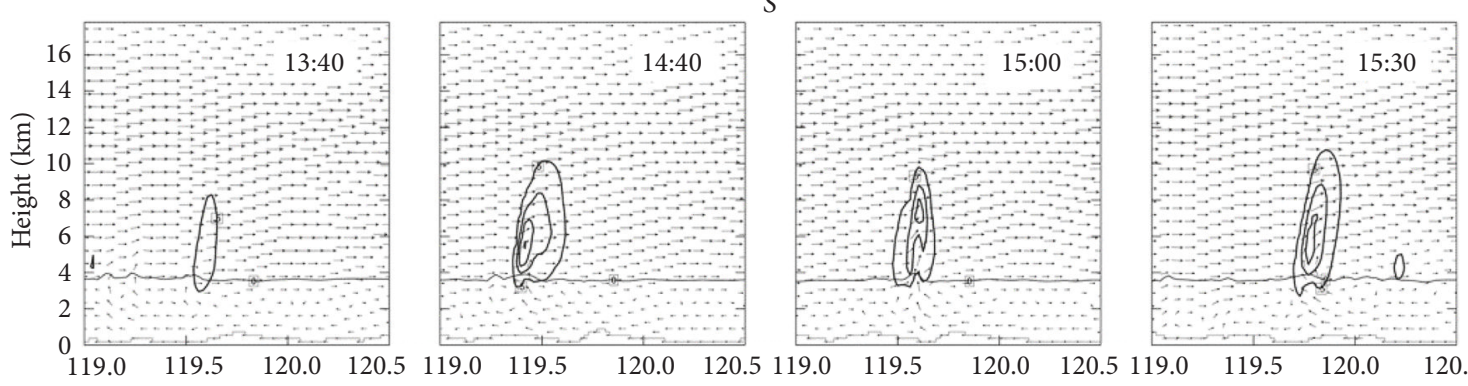

(b)
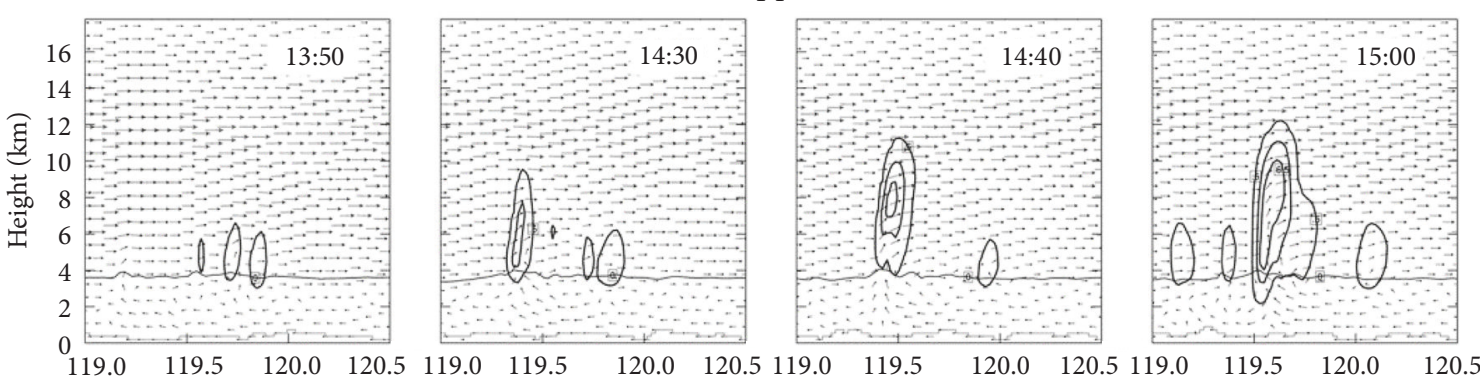

(c)
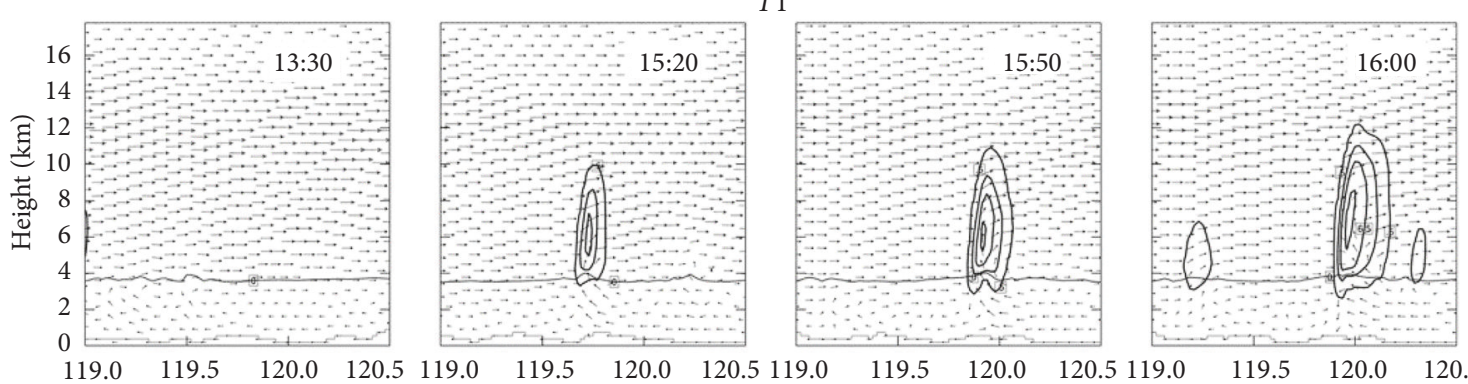

(d)

T2
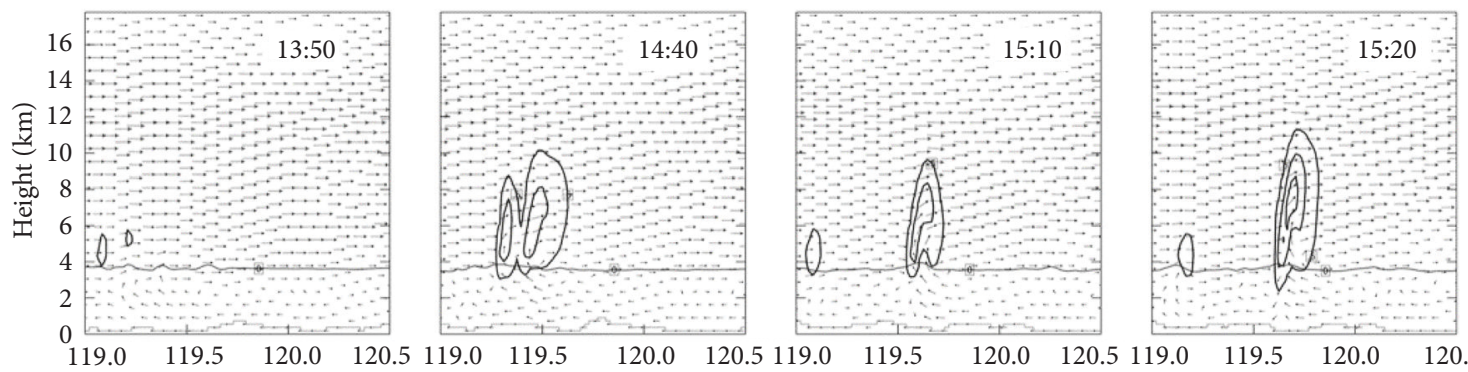

(e)

Figure 10: Continued. 

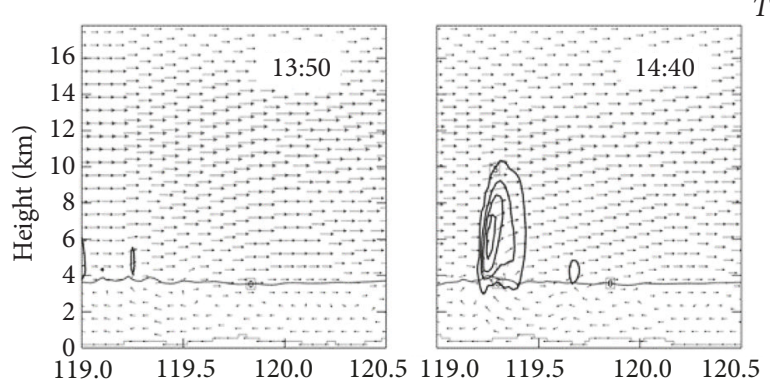

$T 2$
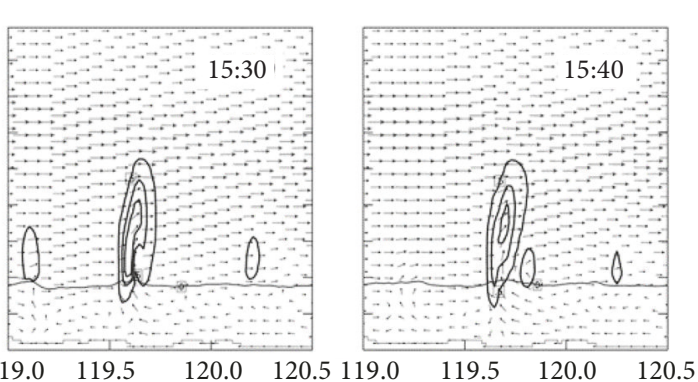

(f)

FIGURE 10: Cross section of the simulated graupel water mixing ratio (solid line, minimum $0.5 \mathrm{~g} \cdot \mathrm{kg}^{-1}$, interval $3 \mathrm{~g} \cdot \mathrm{kg}^{-1}$ ), $\mathrm{UW}$ wind vector, and $0^{\circ} \mathrm{C}$ line (thin solid line) in latitudinal direction based on the different schemes: (a) the original scheme; (b) Philips; (c) Cooper; (d) Fletcher; (e) Chi_NJ; and (f) Chi_Mt. H.

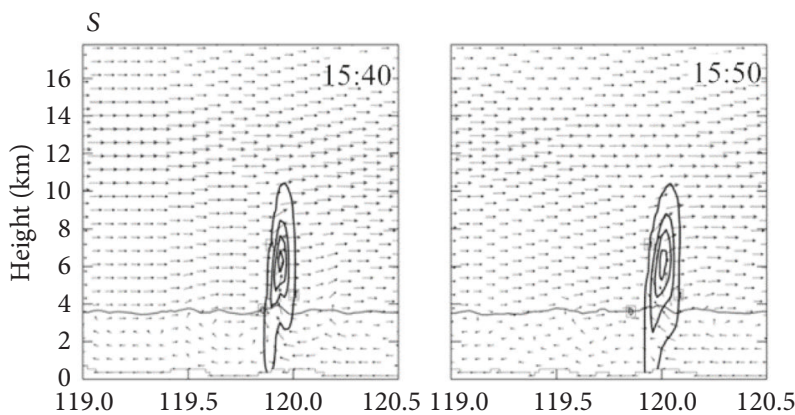

(a)

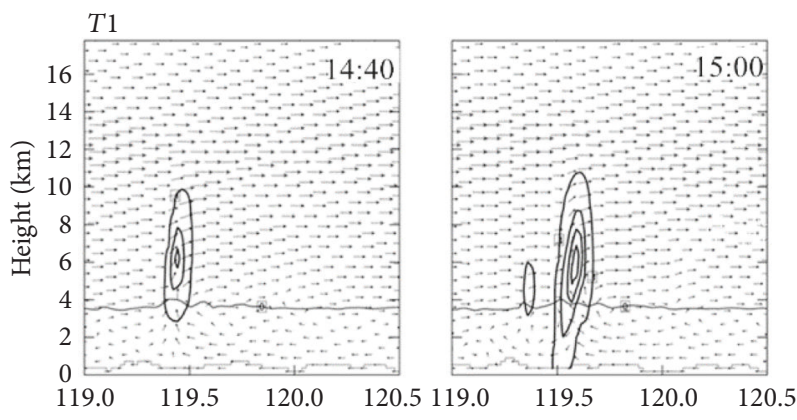

(c)

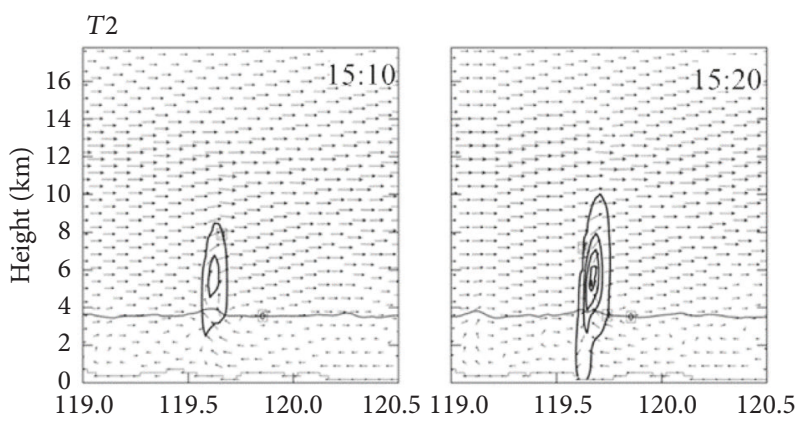

(e)

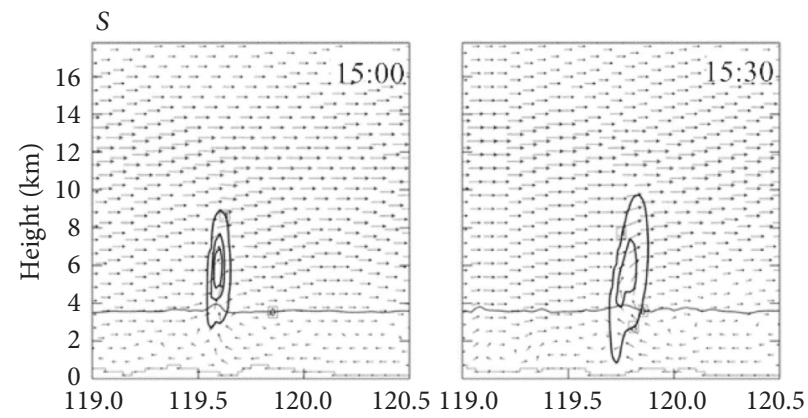

(b)

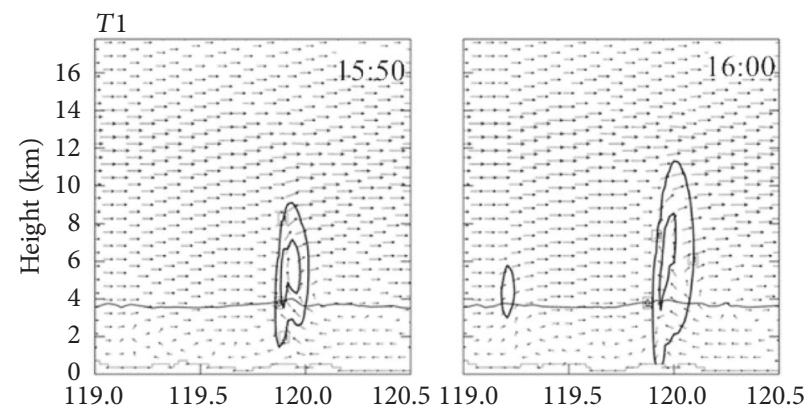

(d)

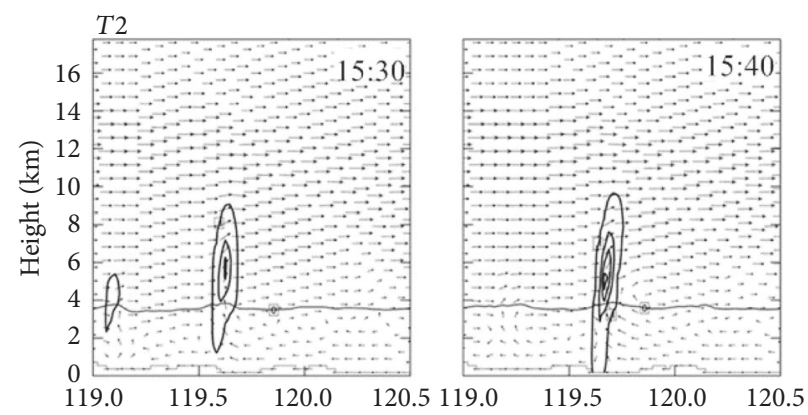

(f)

FIGURE 11: Cross section of the simulated hail water mixing ratio (solid line, minimum $0.1 \mathrm{~g} \cdot \mathrm{kg}^{-1}$, interval $1 \mathrm{~g} \cdot \mathrm{kg}^{-1}$ ), UW wind vector, and $0^{\circ} \mathrm{C}$ line (thin solid line) in latitudinal direction based on the different schemes: (a) original scheme; (b) Philips; (c) Cooper; (d) Fletcher; (e) Chi_NJ; and (f) Chi_Mt. H. 
hand, this allows more time for hail particles to grow via the collection of ice, snow particles, and supercooled water droplets.

In conclusion, the development of hail storms and their dependency on IN are very complex. In the future, the temporal and spatial variations of IN should be considered in the simulation of severe precipitation based on highprecision observations of aerosol characteristics such as the physical and chemical properties of aerosol particles and IN activation properties of aerosols.

\section{Conflicts of Interest}

The authors declare that they have no conflicts of interest.

\section{Acknowledgments}

This research was supported by the National Natural Science Foundation of China (41375137, 11403106, 41505118, and 41505121), Open Funding from the Key Laboratory of Meteorological Disaster of the Ministry of Education, China (KLME1205), and Science Technology Foundation of the State Grid Corporation of China (1704-00203).

\section{References}

[1] K. M. Lau and H. T. Wu, "Warm rain processes over tropical oceans and climate implications," Geophysical Research Letters, vol. 30, no. 24, Article ID 2290, 2003.

[2] Y. Wang, X. Liu, C. Hoose, and B. Wang, "Different contact angle distributions for heterogeneous ice nucleation in the community atmospheric model version 5," Atmospheric Chemistry and Physics, vol. 14, no. 19, pp. 10411-10430, 2014.

[3] W.-K. Tao, X. Li, A. Khain, T. Matsui, S. Lang, and J. Simpson, "Role of atmospheric aerosol concentration on deep convective precipitation: Cloud-resolving model simulations," Journal of Geophysical Research: Atmospheres, vol. 112, article D24S18, no. 24, 2007.

[4] Z. Levin and W. R. Cotton, Aerosol Pollution Impact on Precipitation: A Scientific Review, Springer, 2009.

[5] A. Khain, D. Rosenfeld, and A. Pokrovsky, "Aerosol impact on the dynamics and microphysics of deep convective clouds," Quarterly Journal of the Royal Meteorological Society, vol. 131, no. 611, pp. 2639-2663, 2005.

[6] L. Xu, L. J. Jin, Z. R. Tan et al., "Recent advances in influence of atmospheric aerosol particles on deep convective cloud and precipitation," Journal of Anhui Agricultural Sciences, vol. 38, no. 6, pp. 3309-3312, 2010 (Chinese).

[7] S. A. Changnon Jr., "More on the La Porte Anomaly: A review," Bulletin of the American Meteorological Society, vol. 61, no. 7, pp. 702-711, 1980.

[8] A. P. Khain, L. R. Leung, B. Lynn, and S. Ghan, "Effects of aerosols on the dynamics and microphysics of squall lines simulated by spectral bin and bulk parameterization schemes," Journal of Geophysical Research: Atmospheres, vol. 114, no. 22, Article ID D22203, 2009.

[9] S. C. van den Heever, G. G. Carrió, W. R. Cotton, P. J. DeMott, and A. J. Prenni, "Impacts of nucleating aerosol on Florida storms. Part I: Mesoscale simulations," Journal of the Atmospheric Sciences, vol. 63, no. 7, pp. 1752-1775, 2006.
[10] G. G. Carrió, S. C. van den Heever, and W. R. Cotton, "Impacts of nucleating aerosol on anvil-cirrus clouds: A modeling study," Atmospheric Research, vol. 84, no. 2, pp. 111-131, 2007.

[11] M. P. Meyers, P. J. Demott, and W. R. Cotton, "New primary ice-nucleation parameterizations in an explicit cloud model," Journal of Applied Meteorology and Climatology, vol. 31, no. 7, pp. 708-721, 1992.

[12] P. J. Connolly, O. Möhler, P. R. Field et al., "Studies of heterogeneous freezing by three different desert dust samples," Atmospheric Chemistry and Physics, vol. 9, no. 8, pp. 2805-2824, 2009.

[13] N. H. Fletcher, The Physics of Rainclouds, University Press, Cambridge, UK, 1962.

[14] A. E. Carte and S. C. Mossop, "Measurements of the concentration of atmospheric ice nuclei in Southern Africa," Bulletin del' Observalorie du Puy de Dome, vol. 4, pp. 137-149, 1960.

[15] W. A. Cooper and C. P. R. Saunders, "Winter storms over the San Juan Mountains. Part II: microphysical processes.", Journal of Applied Meteorology and Climatology, vol. 19, no. 8, pp. 927$941,1980$.

[16] D. A. Bowdle, P. V. Hobbs, and L. F. Radke, "Particles in the lower troposphere over the High Plains of the United States. Part III: ice nuclei.," Journal of Climate and Applied Meteorology, vol. 24, no. 12, pp. 1370-1376, 1985.

[17] L. G. You and A. Y. Shi, "The measurement and analysis of icenucleus concentration at Peking during the period from March 18th to April 30th in 1963," Acta Meteorologica Sinica, vol. 34, no. 4, pp. 548-554, 1964 (Chinese).

[18] L. G. You, S. Z. Yang, X. G. Wang et al., "Study of ice nuclei concentration at Beijing in spring of 1995 and 1996," Acta Meteorologica Sinica, vol. 60, no. 1, pp. 101-109, 2002 (Chinese).

[19] L. G. You, G. Y. Xiong, M. R. Gao et al., "Study on the ice crystal formation and snow growth in stratiform cloud in spring of Jilin area," Acta Meteorologica Sinica, vol. 35, no. 4, pp. 423-433, 1965 (Chinese).

[20] I. Gultepe, G. A. Isaac, and S. G. Cober, "Ice crystal number concentration versus temperature for climate studies," International Journal of Climatology, vol. 21, no. 10, pp. 1281-1302, 2001.

[21] A. V. Korolev, G. A. Isaac, S. G. Cober, J. W. Strapp, and J. Hallett, "Microphysical characterization of mixed-phase clouds," Quarterly Journal of the Royal Meteorological Society, vol. 129, no. 587, pp. 39-65, 2003.

[22] P. J. Huffman, "Supersaturation spectra of AgI and Natural ice nuclei," Journal of Applied Meteorology and Climatology, vol. 12, no. 6, pp. 1080-1082, 1973.

[23] P. J. DeMott, D. C. Rogers, and S. M. Kreidenweis, "The susceptibility of ice formation in upper tropospheric clouds to insoluble aerosol components," Journal of Geophysical Research: Atmospheres, vol. 102, no. 16, pp. 19575-19584, 1997.

[24] O. Möhler, P. R. Field, P. Connolly et al., "Efficiency of the deposition mode ice nucleation on mineral dust particles," Atmospheric Chemistry and Physics, vol. 6, no. 10, pp. 3007-3021, 2006.

[25] G. Vali, "Nucleation terminology," Journal of Aerosol Science, vol. 16, no. 6, pp. 575-576, 1985.

[26] G. De Boer, H. Morrison, M. D. Shupe, and R. Hildner, "Evidence of liquid dependent ice nucleation in high-latitude stratiform clouds from surface remote sensors," Geophysical Research Letters, vol. 38, article L01803, no. 1, 2011.

[27] C. Hoose, U. Lohmann, R. Erdin, and I. Tegen, "The global influence of dust mineralogical composition on heterogeneous 
ice nucleation in mixed-phase clouds," Environmental Research Letters, vol. 3, article 025003, no. 2, 2008.

[28] P. J. DeMott, D. C. Rogers, S. M. Kreidenweis et al., “The role of heterogeneous freezing nucleation in upper tropospheric clouds: Inferences from SUCCESS," Geophysical Research Letters, vol. 25, no. 9, pp. 1387-1390, 1998.

[29] Y.-L. Lin, R. L. Deal, and M. S. Kulie, "Mechanisms of cell regeneration, development, and propagation within a twodimensional multicell storm," Journal of the Atmospheric Sciences, vol. 55, no. 10, pp. 1867-1886, 1998.

[30] K. Diehl and S. Wurzler, "Air parcel model simulations of a convective cloud: Bacteria acting as immersion ice nuclei," Atmospheric Environment, vol. 44, no. 36, pp. 4622-4628, 2010.

[31] A. L. Shi, G. G. Zheng, and L. G. You, "Observation and analysis on ice nuclei of Henan County of Qinghai province in autumn 2003," Journal of Applied Meteorological Science, vol. 17, no. 2, pp. 245-249, 2006 (Chinese).

[32] D. X. Feng, R. Z. Chen, and G. W. Jiang, "A laboratory study on the role og the loess particles as natural ice nuclei," Quarterly Journal of Applied Meteorology, vol. 5, no. 2, pp. 129-134, 1994 (Chinese).

[33] J. X. Zhang, F. J. Liao, Z. Y. Gao et al., "Study on atmospheric ice nuclei on North Slop of Mid Tianshan Mountains in summer," Plateau Meteorology, vol. 25, no. 1, pp. 138-142, 2006 (Chinese).

[34] J. Li and G. Huang, "Analysis of observational results of content of ice nuclei in the atmosphere in the upper reaches of Huanghe river," Meteorological Monthly, vol. 27, no. 11, pp. 8-12, 2001 (Chinese).

[35] S. R. Li, G. Huang, and Z. J. Hu, "Analysis of ice nuclei in atmosphere in Henan County in upper reaches of Huanghe river," Journal of Applied Meteorological Science, vol. 14, no. Supplement, pp. 41-48, 2003 (Chinese).

[36] Y. W. Li and B. Y. Du, "Measurement and analysis of concentration of atmospheric ice nuclei in Tianshan Mountain area," Journal of Nanjing Institute of Meteorology, vol. 26, no. 3, pp. 364-370, 2006 (Chinese).

[37] V. T. J. Phillips, A. Pokrovsky, and A. Khain, "The influence of time-dependent melting on the dynamics and precipitation production in maritime and continental storm clouds," Journal of the Atmospheric Sciences, vol. 64, no. 2, pp. 338-359, 2007.

[38] P. J. DeMott, K. Sassen, M. R. Poellot et al., "African dust aerosols as atmospheric ice nuclei," Geophysical Research Letters, vol. 30, no. 14, Article ID 1732, 2003.

[39] V. T. J. Phillips, P. J. DeMott, and C. Andronache, "An empirical parameterization of heterogeneous ice nucleation for multiple chemical species of aerosol," Journal of the Atmospheric Sciences, vol. 65, no. 9, pp. 2757-2783, 2008.

[40] H. Su, The Observation Study of Number Concentration And Character of Atmospheric Ice Nuclei in Huangshan Area, Nanjing University of Information Science \& Technology, 2013 (Chinese).

[41] L. Yang, Y. Yin, and S. Z. Yang, "Measurement and analysis of atmospheric ice nuclei in Nanjing," Chinese Journal of Atmospheric Science, vol. 37, no. 3, pp. 579-594, 2013 (Chinese).

[42] E. R. Mansell, C. L. Ziegler, and E. C. Bruning, "Simulated electrification of a small thunderstorm with two-moment bulk microphysics," Journal of the Atmospheric Sciences, vol. 67, no. 1, pp. 171-194, 2010.

[43] C. L. Ziegler, "Retrieval of thermal and microphysical variables in observed convective storms. Part 1: model development and preliminary testing.", Journal of the Atmospheric Sciences, vol. 42, no. 14, pp. 1487-1509, 1985.
[44] W. R. Cotton, G. J. Tripoli, R. M. Rauber et al., "Numerical simulation of the effects of varying ice crystal nucleation rates and aggregation processes on orographic snowfall," Journal of Climate and Applied Meteorology, vol. 25, no. 11, pp. 1658-1680, 1986.

[45] H. Xiao, H. L. Yang, and Y. C. Hong, "Numerical simulation of the impacts of ice nuceus spectra on cloud seeding effects in convective storm clouds," Climate and Environmental Research, vol. 17, no. 6, pp. 833-847, 2012 (Chinese). 

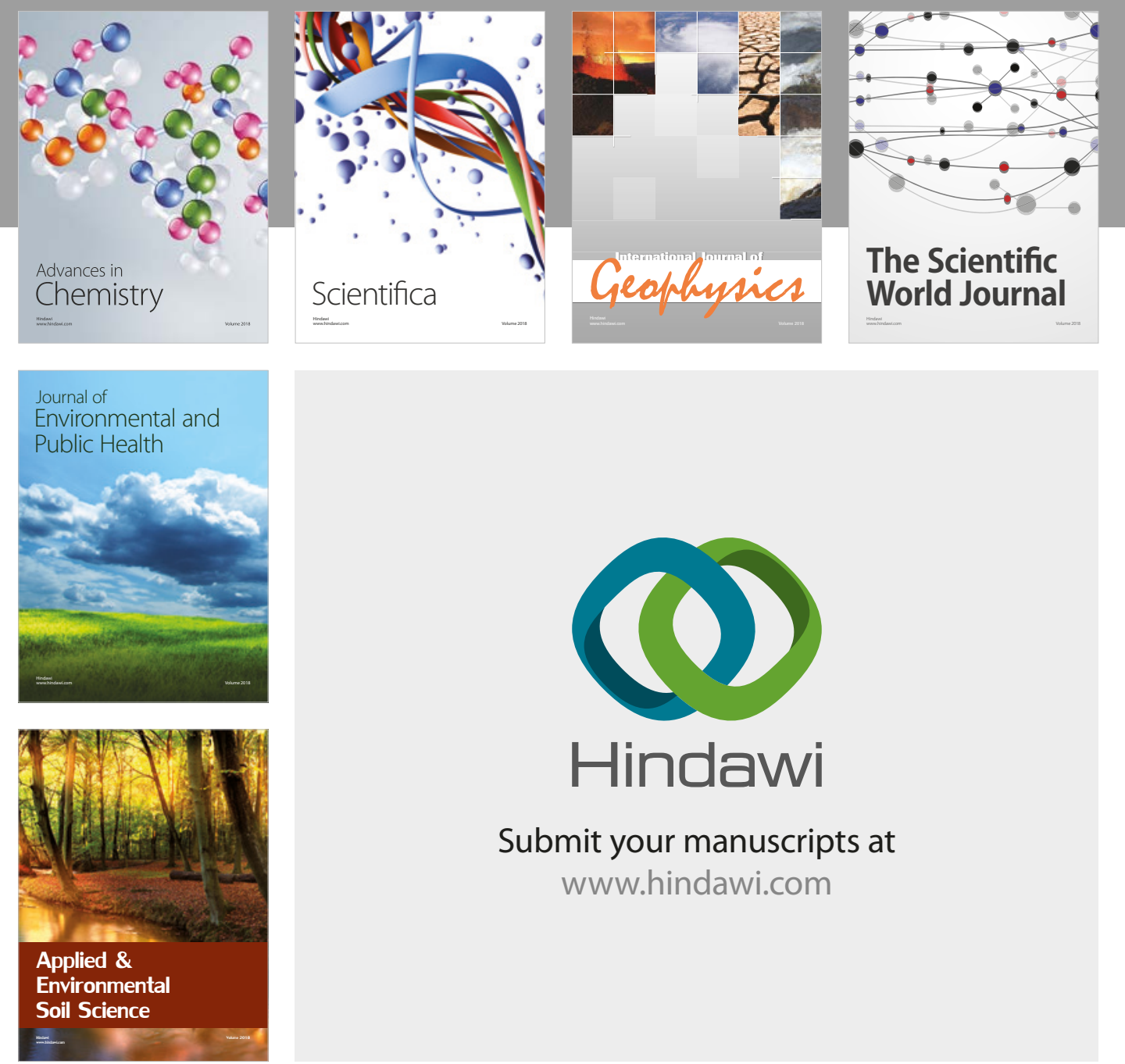

The Scientific

\section{World Journal}
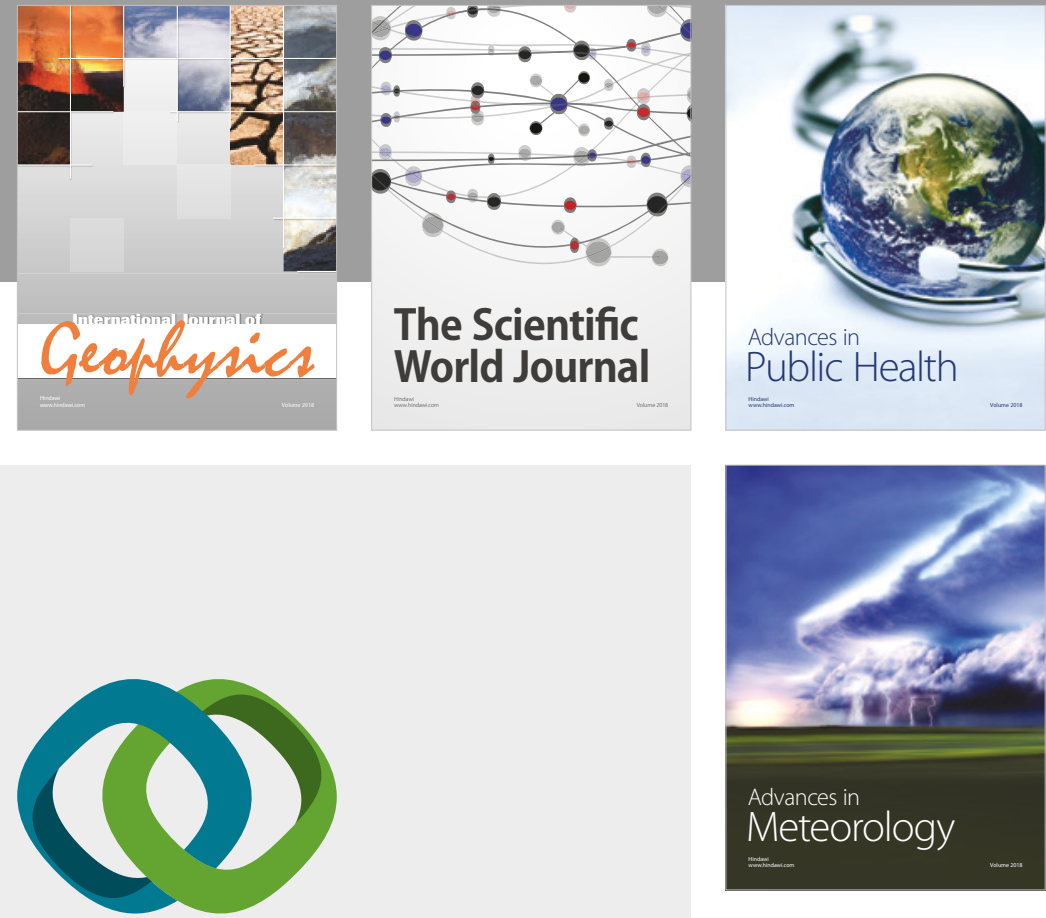

Advan

Public Health

\section{Hindawi}

Submit your manuscripts at

www.hindawi.com
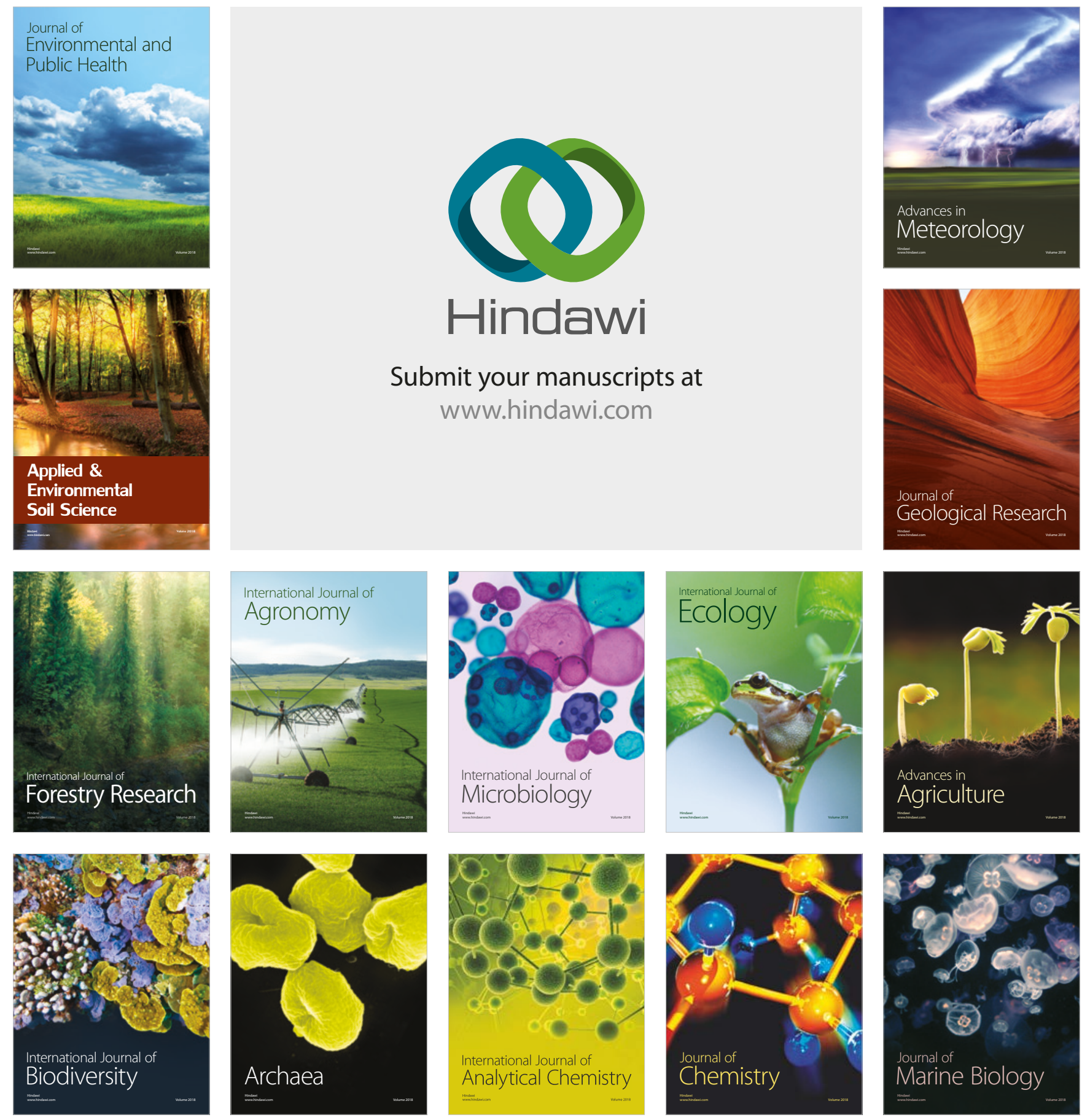